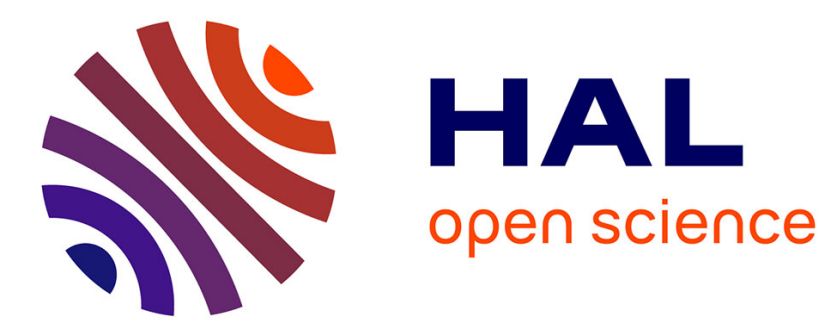

\title{
Labor market institutions and inflation volatility in the euro area
}

\author{
Alessia Campolmi, Ester Faia
}

\section{To cite this version:}

Alessia Campolmi, Ester Faia. Labor market institutions and inflation volatility in the euro area. Journal of Economic Dynamics and Control, 2011, 35 (5), pp.793. 10.1016/j.jedc.2010.07.001 . hal00796300

\section{HAL Id: hal-00796300 \\ https://hal.science/hal-00796300}

Submitted on 3 Mar 2013

HAL is a multi-disciplinary open access archive for the deposit and dissemination of scientific research documents, whether they are published or not. The documents may come from teaching and research institutions in France or abroad, or from public or private research centers.
L'archive ouverte pluridisciplinaire HAL, est destinée au dépôt et à la diffusion de documents scientifiques de niveau recherche, publiés ou non, émanant des établissements d'enseignement et de recherche français ou étrangers, des laboratoires publics ou privés. 


\section{Author's Accepted Manuscript}

Labor market institutions and inflation volatility in the euro area

Alessia Campolmi, Ester Faia

PII:

S0165-1889(10)00161-2

DOI: doi:10.1016/j.jedc.2010.07.001

Reference: DYNCON 2461

To appear in: $\quad$ Journal of Economic Dynamics

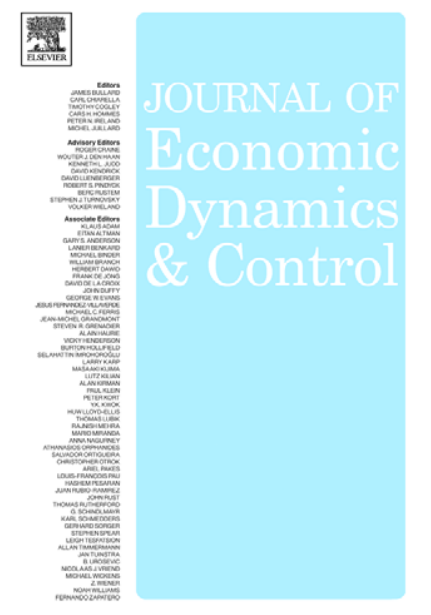
\& Control

www.elsevier.com/locate/jedc

Cite this article as: Alessia Campolmi and Ester Faia, Labor market institutions and inflation volatility in the euro area, Journal of Economic Dynamics \& Control, doi:10.1016/j.jedc.2010.07.001

This is a PDF file of an unedited manuscript that has been accepted for publication. As a service to our customers we are providing this early version of the manuscript. The manuscript will undergo copyediting, typesetting, and review of the resulting galley proof before it is published in its final citable form. Please note that during the production process errors may be discovered which could affect the content, and all legal disclaimers that apply to the journal pertain. 


\title{
Labor Market Institutions and Inflation Volatility in the Euro Area
}

\author{
Alessia Campolmi ${ }^{\mathrm{a}, \mathrm{b}, 1}$, Ester Faia ${ }^{\mathrm{c}, \mathrm{d}, \mathrm{e}, 2}$ \\ ${ }^{a}$ Central European University, Economics Department, Budapest, Hungary \\ ${ }^{b}$ Magyar Nemzeti Bank, Research Department, Budapest, Hungary \\ ${ }^{c}$ Goethe University Frankfurt, Department of Money and Macroeconomics, Frankfurt, Germany \\ ${ }^{d}$ Kiel IfW, Kiel, Germany \\ ${ }^{e}$ CEPREMAP, Paris, France
}

\begin{abstract}
Despite having had the same currency for many years, EMU countries still have quite different inflation dynamics. In this paper we explore one possible reason: country specific labor market institutions, giving rise to different inflation volatilities. When unemployment insurance schemes differ, as they do in EMU, reservation wages react differently in each country to area-wide shocks. This implies that real marginal costs and inflation also react differently. We report evidence for EMU countries supporting the existence of a cross-country link over the cycle between labor market structures on the one side and real wages and inflation on the other. We then build a DSGE model that replicates the data evidence. The inflation volatility differentials produced by asymmetric labour markets generate welfare losses at the currency area level of approximately $0.3 \%$ of steady state consumption.
\end{abstract}

Key words: inflation volatility, labor market institutions, EMU.

JEL Codes: E52, E24

\section{Introduction}

Inflation differentials are still pronounced among euro area countries despite the existence, for many years, of a common currency, a single market for products, capital and labor (though with low labor mobility) and tightly harmonized fiscal policies. Why is it so? Research to date has concentrated on differentials in inflation levels, explaining their size and persistence on the basis of convergence mechanisms such as the "Balassa Samuelson", or asymmetric national shocks (in aggregate demand, or supply, or in the degree of exposure to area-wide external shocks), whose effect are typically exacerbated by high inflation persistence ${ }^{3}$. Here we look instead at inflation volatility differentials and study their link with labor market institutions specifically, the degree of coverage of unemployment insurance.

We thank Ignazio Angeloni, Luca Dedola, Jordi Gali' and seminar participants at Universitat Pompeu Fabra, European Central Bank, LUISS, Universita' di Tor Vergata and conference participants at the Magyar Nemzeti Bank workshop on "Labor Market, Wage behavior and Inflation Dynamics", CEPR/EUI conference on "Globalization, EMU and the Reshaping of the European Economies", Riksbank conference on "Structural Analysis of Business Cycle in Open Economy", the Society for Economics Dynamics 2005, World Congress of the Econometric Society 2005, European Economic Association Meeting 2005, Csef-Igier Symposium on Economic and Institutions. Ester Faia gratefully acknowledges financial support from the DSGE grant of the Spanish Ministry and Unicredit research grant. Alessia Campolmi gratefully acknowledges financial support from Marco Polo grant of Universita' di Bologna.

Email addresses: campolmia@ceu.hu (Alessia Campolmi), faia@wiwi.uni-frankfur (Ester Faia)

${ }^{1}$ Homepage: http://www.personal.ceu.hu/departs/personal/Alessia_Campolmi

${ }^{2}$ Homepage: http://www.wiwi.uni-frankfurt.de/profs/faia/

${ }^{3}$ See ECB (2003) for a non-technical survey and Honohan and Lane (2003), Angeloni and Ehrmann (2007) and the references therein, for some interpretations of the evidence.

Preprint submitted to Elsevier

November 18, 2009 
We think that the properties of euro area inflation we document and the explanation we offer may be deeper and more long-lasting than those studied by other authors. While convergence phenomena are by nature transient, and inflation persistence in the eurozone can be expected to decline as a result of product market reforms and enhanced central bank credibility, labor market structures (unemployment insurance in particular) are deeply entrenched in national preferences ${ }^{4}$ and hence should be expected to vary little over time. Linking them to inflation volatility differentials ${ }^{5}$ hence means pointing at features of inflation asymmetry in the EMU that will be very difficult to remove, even at much higher levels of economic and financial integration than today.

Labor market characteristics influence the dynamics of real wages and of the marginal cost of firms, which, in the standard New-Keynesian model, are a main driver of inflation. Hence it seems natural to assess the quantitative relevance of such institutions in determining differentials in inflation behavior. We do so in two steps. We first document a negative empirical relation between volatilities of de-trended real wages and inflation and replacement rates $^{6}$ during the EMU period. Secondly, we build a DSGE model with two countries sharing the same currency, characterized by matching frictions with Nash bargaining and wage rigidity in the labor market $^{7}$, monopolistic competition and adjustment cost on pricing. The two-country model accounts for the rich structure of propagation mechanisms and international spillovers existing in a monetary union. We use this laboratory economy, calibrated on the euro area, to analyze the effect of shocks under different values of the replacement rates, and find that the model also gives rise to a negative relation. Finally, we match the model results with the empirical ones, and find that the model replicates well the relations found in the data.

The intuition behind our reasoning is the following. In countries with higher replacement rate (ratio between unemployment benefit and wage), workers face a better outside option which expands (steady state) wages and compresses (steady state) profits. Assuming little or no labor mobility, in the country with high replacement rate a given change in productivity induces a higher percentage change in firms' profits. This increases firms' incentives to post vacancies and makes unemployment more volatile. At the same time, wages change less in percentage terms, because they are already relatively large in absolute terms in the steady state. In other words higher replacement rates prevent wages from fully absorbing the change in productivity $^{8}$. This bears out in the falling volatility of real marginal costs and inflation when replacement rates are higher.

The mechanism described so far would characterize equally well a closed economy model with matching frictions and endogenous separation, however we show that it is reinforced in the open economy. Recall that workers' total income is evaluated in terms of CPI indices (which includes prices of foreign goods) while firms' profits and wage offers are evaluated in terms of domestic inflation: a consequence of this mismatch between firms and workers surplus is that terms of trade (defined as domestic over foreign prices) enter the wage schedule as determined by the standard Nash bargaining rule. For given replacement rate in the foreign country, a higher replacement rate in the home country has two effect. First, it reduces wage and inflation volatility because of the above-mentioned mechanism. Second, the fall in domestic inflation reduces terms of trade volatility (for given correlation between domestic and foreign inflation) which in turn induces further reductions in wage volatility.

\footnotetext{
${ }^{4}$ See Sapir (2006).

${ }^{5}$ Different unemployment benefits lead to different steady state unemployment rates. However steady state (gross) inflation is always one to the extent that there are no long run differences in productivity (Balassa Samuelson effect). Hence different labour market institutions lead mainly to differences in the dynamic of inflation across countries. Notice that even if long run differences in productivity arise they do not constitute a concern for the policy maker for two reasons. First, they vanish as the convergence process takes place (catch up effect). Second, differences in productivity, even when they apply, do not lead to differences in efficiency and welfare across countries.

${ }^{6}$ As calculated by Nickell and Nunziata (2007).

${ }^{7}$ The tradition of introducing matching frictions in DSGE closed economy model is well established. See Merz (1995), Andolfatto (1996), Cooley and Quadrini (1999), Shimer (2005), Hall (2005) among many others.

${ }^{8}$ See for a similar link in closed economy models Pissarides (2000) and Hagedorn and Manovskii (2008).
} 
Given that the model used is suited to conduct a welfare analysis, we do so and find that asymmetries in labour market structure across the two countries give rise to welfare losses at the union level of around $0.3 \%$ of steady state consumption.

Our paper is related to a growing body of literature studying the impact of wage rigidity and nonmarket return to workers on the volatility of wage and unemployment ${ }^{9}$. It is also related to several recent contributions pursuing a new synthesis between the new keynesian model and the non-walrasian theory of unemployment ${ }^{10}$. Our is the first contribution that introduces a non-walrasian theory of unemployment into new open economy framework. The specific focus of this paper is on the role of labor market institutions for relative volatilities, but the analysis highlights several other interesting features of the model. Finally our paper is related to other studies on inflation differentials. Inflation differentials arise because of differences in long run inflation process or because of differences in the cyclical component of inflation. We focus on the cyclical component for various reasons. First, long run differences in the inflation process are due to differences in productivity which per se do not lead to differences in inefficiency and which are normally absorbed within a decade. Second, several empirical studies (see Alberola (2000), Rogers (2002) and Ortega (2003)) show that factors other than differences in long run productivity levels play a significant role in explaining price and inflation divergence in Europe. In particular they stress the importance of wages differences as main determinant of inflation differentials.

In section 2 we present our empirical stylized facts; in section 3 we present the model and its calibration, in section 4 we show the model results and we match them with the data. Section 5 presents the welfare analysis and section 6 concludes.

\section{Data Analysis}

Table 1 shows the replacement rates for a series of euro area countries in the year 2004. Data are taken from Nickell and Nunziata (2007). As a measure of unemployment insurance coverage they use the benefit replacement rate (BBR, benefit as a ratio to average earnings before taxes) provided by OECD, which is a measure of the monetary loss incurred by the worker when moving from the employed to the unemployed status. To proxy a dynamic concept of unemployment insurance benefit, Nickell and Nunziata calculate a weighted average of the BRR over the first 5 years of unemployment. Because of this transformation their measure is able to capture long run effects of changes in replacement rates better than the corresponding simple BRR provided by the OECD dataset.

Several features of the data are worth noting. First, there is considerable cross-country variation, from a minimum of 0.30 to a maximum of 0.86 ; this seems a large enough span to have an observable macroeconomic impact. It is worth noticing that we observe much cross-country variation but little time variation $^{11}$, suggesting that indeed the BRR incorporates deeply entrenched features of the national systems. In the literature this parameter is often use as a catch-all measure of unemployment insurance, and is assumed to be a key determinant in the worker's decision to keep a job. A further advantage of this index is that, being a monetary variable, it is easily measurable and comparable across countries. Finally Nickell (1997) and Blanchard and Wolfers (2000) show that this institution has a statistically significant influence on labor market dynamics, while Pissarides (2000), chapter 9 stresses that this variable is particularly relevant in explaining structural labor market characteristics. All those considerations make this measure particularly appealing as best proxy of labor market institutions.

\footnotetext{
${ }^{9}$ See Shimer (2005), Hall (2005), Costain and Reiter (2008), Hagedorn and Manovskii (2008), Zanetti (2007).

${ }^{10}$ Several paper ranging from Walsh (2003) to Krause and Lubik (2005) study the role of matching frictions in new keynesian models. Blanchard and Galí (2007), Faia (2008) and Thomas (2008) also study optimal monetary policies in new keynesian models with matching frictions.

${ }^{11}$ Despite the fact that some countries have undertaken reforms in the last decade there is still a considerable cross-country variation. In comparing replacement rates data across different periods (pre and post EMU) we came across two observations. First, all EMU countries have undertaken reforms that increased the size and duration of the unemployment benefits. Secondly, despite those reforms the relative ranking across countries remained the same as there was still little convergence.
} 
In our analysis we consider the euro area countries during the period 1998Q1-2007Q4 ${ }^{12}$. 1998 is included in the sample because during most of that year exchange rates were virtually constant and EMU was expected with certainty to start at the beginning of the following year (in fact, the ECB was created in mid-1998, not in 1999 as often assumed). Among the original EMU members, we exclude Luxembourg because there are no data on replacement rates, hence making a total of 10 countries $^{13}$. Although the time span is not too long for the fact that the euro area is a recent experience, it is long enough to carry a meaningful data analysis based on second moments. We will return on this later on.

In figure 1 we plot on the vertical axis the volatilities of wage and inflation, all measured relative to the volatility of output in the corresponding countries ${ }^{14}$, and on the horizontal axis the replacement rates ${ }^{15}$.

Inflation rates are measured by the GDP deflator. Following most of the literature as measure of real wages we use the hourly earnings divided by the CPI. Data are taken from OECD. The standard deviations have been computed on Hodrick-Prescott filtered series ${ }^{16}$. In both charts we drew two interpolating lines, a linear and an exponential one, and reported the corresponding $R^{2}$. The lines shows a negative relation, and the exponential is convex relative to the origin. The evidence of a negative and convex relation seems quite clear and robust across the two measures of volatility.

Figure 2 shows the same variables, but this time as ratios between pairs of countries. Hence each dot shows, for a given pair of countries, the ratio between the standard deviations (relative to that of output) of real wages and inflation, respectively, plotted against the corresponding ratios of the replacement rates. We show these transformations of the original data because this is the appropriate way to match the model results with the data, as explained below. The negative relation, linear and non-linear, is again clear.

To test the robustness of the relation we allowed for different country sample: particularly we replicated the relations (both for the levels and the ratios) by taking out, singularly and in combination, Italy, Spain and Ireland, as particularly the latter country might behave as an outlier due to the high volatility of inflation produced by convergence effect. In all cases we found a clear negative relation.

In order to better evaluate the robustness of these findings, in table 3 and 4 we report the estimated coefficients and the $R^{2}$ of both the non linear (first column) and linear regression (column (1)) for, respectively, inflation volatility and wage volatility. In all cases the estimated coefficients are negative and statistically significant at $10 \%$ level $^{17}$. As an additional test to the robustness of the results, we consider two additional measures of labour market structure: employment protection legislation (EPL) and union density (UD). The latest available measure for EPL refers to 2003 and is available on the OECD Employment Outlook (2004). Two indexes are available, we consider both. UD is also available in the OECD website and we take the value at 2004, consistently with the Replacement Rate measure. We run again the linear regression including those variables as controls (one at the time). For inflation volatility the coefficient of the replacement rate remains always negative and significant displaying also little variation. The same is true also for the wage volatility regressions even though here the coefficient is not always significant. We do the same analysis for the ratios (tables 5 and 6). Again, the replacement rate has always a negative and significant coefficient, in all specifications.

Despite the fact that time span available to us, from the start of the euro to present, is quite short and limits data availability, it is possible to conclude that there is a consistent path linking replacement rates, inflation and wages. As this path was robust under different time and country sample the analysis points out at a clear trend characterizing euro area data. The relations found in the data allow us to draw a relevant number of information. First, since the negative link exists for both variables considered (wages and

\footnotetext{
${ }^{12}$ We do not include 2007 for the wages because in the OECD database hourly earnings for Germany are available only up to 2006 .

${ }^{13}$ For the real wage, also Portugal is missing because of the too short sample available.

${ }^{14}$ We divided by the volatility of output to have a standardized measure.

${ }^{15}$ As reported in table 1.

${ }^{16}$ Hodrick-Prescott filters have been computed by considering time spans of at least ten years.

${ }^{17}$ For the inflation volatility significance is reached when Ireland is excluded from the sample consistently with the high inflation volatility experienced by this country during the convergence period
} 
inflation) there seem to be an important supply side mechanism explaining differentials in inflation volatility. Secondly, a model aimed at explaining these patterns should highlight the role of non-market returns on the threat point of the bargaining process in a way that higher outside options dampen wage response to shocks. Based on those assumptions we build the model presented in the next section and we assess all the relevant blocks of the transmission mechanism.

\section{A Model for A Currency Area with Labor Market Frictions}

Each economy is populated by households who consume different varieties of domestically produced and imported goods, save and work. Households save in bonds which are traded within the currency area. Each agent can be either employed or unemployed. In the first case he receives a wage that is determined according to a Nash bargaining, in the second case he receives an unemployment benefit. The labor market is characterized by matching frictions and endogenous job separation. The production sector acts as a monopolistic competitive sector which produces a differentiated good using capital and labor as inputs and faces adjustment costs a' la Rotemberg (1982).

\subsection{Households in the Domestic and Foreign Country}

Let's denote by $c_{t} \equiv\left[(1-\gamma)^{\frac{1}{\eta}} c_{h, t}^{\frac{\eta-1}{\eta}}+\gamma^{\frac{1}{\eta}} c_{f, t}^{\frac{\eta-1}{\eta}}\right]^{\frac{\eta}{\eta-1}}$ a composite consumption index of domestic and imported bundles of goods, where $\gamma$ is the balanced-trade steady state share of imported goods (i.e., an inverse measure of home bias in consumption preferences), and $\eta>0$ is the elasticity of substitution between domestic and foreign goods. Optimal allocation of expenditure between domestic and foreign bundles yields:

$$
c_{h, t}=(1-\gamma)\left(\frac{p_{h, t}}{p_{t}}\right)^{-\eta} c_{t} ; c_{f, t}=\gamma\left(\frac{p_{f, t}}{p_{t}}\right)^{-\eta} c_{t}
$$

Each bundle is then composed of imperfectly substitutable varieties (with elasticity of substitution $\varepsilon>1$ ). There is a continuum of agents who maximize the expected lifetime utility:

$$
E_{t}\left\{\sum_{t=0}^{\infty} \beta^{t} \frac{c_{t}^{1-\sigma}}{1-\sigma}\right\}
$$

where $c$ denotes aggregate consumption in final goods. Households supply labor hours inelastically $h$ (which we normalize to 1). Total real labor income is given by $w_{t}$ and is specified below. Unemployed households members, $u_{t}$, receive an unemployment benefit, $b$. The contract signed between the worker and the firm specifies the wage and is obtained through a Nash bargaining process. In order to finance consumption at time $t$ each agent also invests in domestic non-state contingent nominal bonds $b_{t}$, denominated in domestic currency, which are traded in the currency area and pay a gross nominal interest rate $\left(1+r_{t}^{n}\right)$ one period later. Since we are in a currency area with single monetary authority domestic and foreign agents face the same nominal interest rate. As in Andolfatto (1996) and Merz (1995) it is assumed that workers can insure themselves against earning uncertainty and unemployment. For this reason the wage earnings have to be interpreted as net of insurance costs. Finally, agents receive profits from the monopolistic sector which they own, $\Theta_{t}$, and pay lump sum taxes, $\tau_{t}$. The sequence of budget constraints in terms of domestic CPI consumption goods reads as follows:

$$
c_{t}+\frac{b_{t}}{p_{t}} \leq w_{t}\left(1-u_{t}\right)+b u_{t}+\frac{\Theta_{t}}{p_{t}}-\frac{\tau_{t}}{p_{t}}+\left(1+r_{t-1}^{n}\right) \frac{b_{t-1}}{p_{t}}
$$

Households choose the set of processes $\left\{c_{t}, b_{t}\right\}_{t=0}^{\infty}$ taking as given the set of processes $\left\{p_{t}, w_{t}, r_{t}^{n}\right\}_{t=0}^{\infty}$ and the initial wealth $b_{0}$ so as to maximize (2) subject to (3). The following optimality conditions must hold: 


$$
\begin{gathered}
c_{t}^{-\sigma}=\beta\left(1+r_{t}^{n}\right) E_{t}\left\{c_{t+1}^{-\sigma} \frac{p_{t}}{p_{t+1}}\right\} \\
c_{t}^{-\sigma}=\lambda_{t}
\end{gathered}
$$

Equation (4) is the Euler condition with respect to bonds. Equations (5) is the marginal utility of consumption. Optimality requires that No-Ponzi condition on wealth is also satisfied.

Workers in the Foreign Region. We assume throughout that all goods are traded, that both countries face the same composition of consumption bundle and that the law of one price holds. This implies that $p_{h, t}=p_{h, t}^{*}$ and $p_{f, t}=p_{f, t}^{*}$. Under the currency union assumption the nominal exchange rate is equal one. Foreign workers face an allocation of expenditure and wealth similar to the one of workers in the domestic region. The efficiency condition for bonds' holdings will read as follow:

$$
\left(c_{t}^{*}\right)^{-\sigma}=\beta\left(1+r_{t}^{n}\right) E_{t}\left\{\left(c_{t+1}^{*}\right)^{-\sigma} \frac{p_{t}^{*}}{p_{t+1}^{*}} \frac{e_{t+1}^{r}}{e_{t}^{r}}\right\}
$$

where $e_{t}^{r}$ is the real exchange rate which in the currency area is given by $e_{t}^{r}=\frac{p_{t}}{p_{t}^{*}}$. All other optimality conditions are like in the home region. After merging equation (4) with (6) we obtain the following relation:

$$
E_{t}\left\{\frac{\lambda_{t+1}^{*}}{\lambda_{t}^{*}}\right\}=E_{t}\left\{\frac{\lambda_{t+1}}{\lambda_{t}} \frac{e_{t+1}^{r}}{e_{t}^{r}}\right\}
$$

\subsection{The Production Sector In the Domestic and the Foreign Region}

The maximization problems which characterize the production sector ${ }^{18}$ are symmetric across the two economies. In the next section we show only the ones for the home region. Firms in the production sector sell their output in a monopolistic competitive market and meet workers on a matching market. The labor relations are determined according to a standard Mortensen and Pissarides (1999) framework.

\subsubsection{Search and Matching in the Labor Market of the Home Region}

The search for a worker involves a fixed cost $\kappa$ and the probability of finding a worker depends on a constant return to scale matching technology which converts unemployed workers $u$ and vacancies $v$ into matches, $m$ :

$$
m\left(u_{t}, v_{t}\right)=m u_{t}^{\xi} v_{t}^{1-\xi}
$$

where $v_{t}=\int_{0}^{1} v_{i, t} d i$. Defining labor market tightness as $\theta_{t} \equiv \frac{v_{t}}{u_{t}}$, the firm meets unemployed workers at rate $q(\theta)=\frac{m\left(u_{t}, v_{t}\right)}{v_{t}}=m \theta_{t}^{-\xi}$, while the unemployed workers meet vacancies at rate $\theta_{t} q\left(\theta_{t}\right)=m \theta_{t}^{1-\xi}$. If the search process is successful, the firm in the monopolistic good sector operates the following technology:

$$
y_{i, t}=z_{t} n_{i, t} \int_{\tilde{a}_{i, t}}^{\infty} a \frac{f(a)}{1-F\left(\tilde{a}_{i, t}\right)} d a=z_{t} n_{i, t} H\left(\tilde{a}_{i, t}\right)
$$

where $z_{t}$ is the aggregate productivity shock which follows a first order autoregressive process, $n_{i, t}$ is the number of workers hired by each firm, and $a$ is an idiosyncratic shock to workers' productivity which is assumed to be identically and independently distributed across firms and times with cumulative distribution function $F:[0, \infty] \rightarrow[0,1]$. It is assumed that the idiosyncratic shock is observed before the firm starts production. The firm will endogenously discontinue the match if the realized shock is below a certain cut-off value, $\tilde{a}_{i, t}$. The threshold for endogenous separation is determined as a function of the state of the economy

\footnotetext{
${ }^{18}$ We follow Krause and Lubik (2005).
} 
using firms' optimality conditions. Matches are destroyed at varying rate $\rho\left(\tilde{a}_{i, t}\right)$ given by the following expression:

$$
\rho\left(\tilde{a}_{i, t}\right)=\rho^{x}+\rho^{n}\left(\tilde{a}_{i, t}\right)\left(1-\rho^{x}\right)
$$

where $\rho^{x}$ is the exogenous break-up rate and $\rho^{n}\left(\tilde{a}_{i, t}\right)=F\left(\tilde{a}_{i, t}\right)$ is the endogenous break-up rate.

We are now in the position to determine the law of motion for the workers employed and the ones seeking for a job. Labor force is normalized to unity. The number of employed people at time $t$ in each firm $i$ is given by the number of employed people at time $t-1$ plus the flow of new matches concluded in period $t-1$ who did not discontinue the match:

$$
n_{i, t}=\left(1-\rho\left(\tilde{a}_{i, t}\right)\right)\left(n_{i, t-1}+v_{i, t-1} q\left(\theta_{t-1}\right)\right)
$$

Finally we define the gross job destruction and job creation rates as follows:

$$
\begin{gathered}
j d_{t}=\rho\left(\tilde{a}_{i, t}\right)-\rho^{x} \\
j c_{t}=\frac{\left(1-\rho\left(\tilde{a}_{i, t}\right)\right) v_{t-1} q\left(\theta_{t-1}\right)}{n_{t-1}}-\rho^{x}
\end{gathered}
$$

\subsubsection{Monopolistic Firms}

Firms in the monopolistic sector (of the home region) use labor to produce different varieties of consumption good and face a quadratic cost of adjusting prices. Wages are determined through the bargaining problem analyzed in the next section. Here we develop the dynamic optimization decision of firms choosing prices, $p_{h, t}^{i}$, number of employees, $n_{i, t}$, number of vacancies, $v_{i, t}$, and the endogenous separation threshold, $\tilde{a}_{i, t}$, to maximize the discounted value of future profits and taking as given the wage schedule. Let's denote the total real wage bill of firm $i$ (measured in CPI goods) by:

$$
W_{i, t}=n_{i, t} \int_{\tilde{a}_{i, t}}^{\infty} w(a) \frac{f(a)}{1-F\left(\tilde{a}_{i, t}\right)} d a
$$

where $w(a)$ denotes the fact that the bargained wage depends on idiosyncratic shock. Equation (14) states that total wage costs are given by all individual wages paid to the mass of workers that are matched with firms whose individual productivity is above endogenous separation threshold. Given the definition of the terms of trade, $s_{t} \equiv \frac{p_{f, t}}{p_{h, t}}$, let's define:

$$
\phi_{t} \equiv \frac{p_{t}}{p_{h, t}}=\left[(1-\gamma)+\gamma s_{t}^{1-\eta}\right]^{\frac{1}{1-\eta}}
$$

as the $C P I / P P I$ ratio. This variable, which can be interpreted as a proxy of the terms of trade, has a crucial role in our analysis. As workers and firms evaluate their income in different consumption units ( and more specifically as workers evaluate their incomes in terms of CPI price index, $p_{t}$, while firms evaluate their profits in terms of domestic price index, the variable $\phi_{t}$ is needed in all cases in which there is a mismatch in the units of account. The economic meaning of this variable is twofold First, this variables summarizes all the international spillovers from one economy to the other: the features characterizing, for instance, the dynamic of domestic prices is transmitted to the foreign economy through $\phi_{t}$. The higher the degree of openness, $\gamma$, the stronger are the international linkages ${ }^{19}$. Secondly, $\phi_{t}$, represents a wedge that by entering the wage equation (see equation (30)) distorts the labor market equilibrium on top and above the search externality associated with the matching framework.

\footnotetext{
${ }^{19}$ Notice that the value of $\gamma$ different than 0.5 characterizes the degree of home bias and determines departures from the purchasing power parity.
} 
The representative firm in the domestic region chooses $\left\{p_{h, t}^{i}, n_{i, t}, v_{i, t}, \tilde{a}_{i, t}\right\}$ to solve the following maximization problem (in real terms):

$$
\operatorname{Max} \Pi_{i, t}=E_{0} \sum_{t=0}^{\infty} \beta^{t} \frac{\lambda_{t} / \phi_{t}}{\lambda_{0} / \phi_{0}}\left\{\frac{p_{h, t}^{i}}{p_{h, t}} y_{t}^{i}-\phi_{t} W_{i, t}-\kappa v_{i, t}-\frac{\psi}{2}\left(\frac{p_{h, t}^{i}}{p_{h, t-1}^{i}}-1\right)^{2} y_{t}\right\}
$$

subject to

$$
\begin{gathered}
\text { s.to: } \quad y_{t}^{i}=\left(\frac{p_{h, t}^{i}}{p_{h, t}}\right)^{-\epsilon} c_{w, t}=z_{t} n_{i, t} H\left(\tilde{a}_{i, t}\right) \\
\text { and: } n_{i, t}=\left(1-\rho\left(\tilde{a}_{i, t}\right)\right)\left(n_{i, t-1}+v_{i, t-1} q\left(\theta_{t-1}\right)\right)
\end{gathered}
$$

where $c_{w, t}=c_{h, t}+c_{h, t}^{*}$, where $\frac{\psi}{2}\left(\frac{p_{h, t}^{i}}{p_{h, t-1}^{i}}-1\right)^{2} y_{t}$ represents the cost of adjusting prices and $\psi$ can be thought as the sluggishness in the price adjustment process and $\kappa$ as the cost of posting vacancies. Let's define $m c_{t}$, the lagrange multiplier on constraint (17), as the marginal cost of firms and $\mu_{t}$, the lagrange multiplier on constraint (18), as the marginal value of one worker. Since all firms will chose in equilibrium the same price and allocation we can now assume symmetry and drop the index $i$. First order conditions for the above problem read as follows:

- $n_{t}$ :

$$
\mu_{t}=m c_{t} z_{t} H\left(\tilde{a}_{t}\right)-\phi_{t} \frac{\partial W_{t}}{\partial n_{t}}+\beta E_{t}\left(\frac{\lambda_{t+1} / \phi_{t+1}}{\lambda_{t} / \phi_{t}}\right)\left(\left(1-\rho\left(\tilde{a}_{t+1}\right)\right) \mu_{t+1}\right)
$$

- $v_{t}$ :

$$
\frac{\kappa}{q\left(\theta_{t}\right)}=\beta E_{t}\left(\frac{\lambda_{t+1} / \phi_{t+1}}{\lambda_{t} / \phi_{t}}\right)\left(\left(1-\rho\left(\tilde{a}_{t+1}\right)\right) \mu_{t+1}\right)
$$

- $p_{h, t}$ :

$$
\frac{c_{w, t}}{y_{t}}\left[1-\left(1-m c_{t}\right) \varepsilon\right]-\psi\left(\pi_{h, t}-1\right) \pi_{h, t}+\beta E_{t}\left(\frac{\lambda_{t+1} / \phi_{t+1}}{\lambda_{t} / \phi_{t}}\right)\left[\psi\left(\pi_{h, t+1}-1\right) \pi_{h, t+1} \frac{y_{t+1}}{y_{t}}\right]=0
$$

- $\tilde{a}_{t}$ :

$$
\mu_{t} \rho^{\prime}\left(\tilde{a}_{t}\right)\left(n_{t-1}+v_{t-1} q\left(\theta_{t-1}\right)\right)+\phi_{t} \frac{\partial W_{t}}{\partial \tilde{a}_{t}}=m c_{t} z_{t} n_{t} H^{\prime}\left(\tilde{a}_{t}\right)
$$

Merging equations (19) and (20) gives the marginal value of an extra worker, $\mu_{t}$, which is obtained by trading-off the cost of maintaining the match with an existing worker with the cost of posting a new vacancy:

$$
\mu_{t}=m c_{t} z_{t} H\left(\tilde{a_{t}}\right)-\phi_{t} \frac{\partial W_{t}}{\partial n_{t}}+\frac{\kappa}{q\left(\theta_{t}\right)}
$$

Notice that the marginal value of a worker is given not only by his marginal productivity net of the marginal costs but contains also an additional component. By maintaining the match with a worker the firm can save on future costs of posting vacancies. This is exactly the long run value of a worker that in matching models reduces the allocative role of wages.

After substituting the marginal value of an extra worker, $\mu_{t}$, into the optimality condition, (22), using the constraint which describes the evolution of employment, (18), and simplifying we obtain a relation between the threshold value and the real wage schedule:

$$
m c_{t} z_{t} \tilde{a}_{t}-w\left(\tilde{a}_{t}\right) \phi_{t}+\frac{\kappa}{q\left(\theta_{t}\right)}=0
$$

This equation implicitly defines the threshold for the idiosyncratic productivity below which jobs are destroyed. Notice that the expression for the threshold depends on the wage schedule. 


\subsubsection{Bellman Equations, Wage Setting and Nash Bargaining}

The wage schedule is obtained through the solution to an individual Nash bargaining process. To solve for it we need first to derive the marginal values of a match for both, firms and workers. Those values will indeed enter the sharing rule of the bargaining process. Let's denote by $V_{t}^{J}\left(a_{t}\right)$ the marginal discounted value of a match for a domestic firm measured in terms of domestic prices (measured in terms of PPI goods):

$$
V_{t}^{J}\left(a_{t}\right)=m c_{t} z_{t} a_{t}-\phi_{t} w_{t}\left(a_{t}\right)+\beta E_{t}\left\{\left(\frac{\lambda_{t+1} / \phi_{t+1}}{\lambda_{t} / \phi_{t}}\right)\left(1-\rho\left(\tilde{a}_{t+1}\right)\right) \int_{\tilde{a}_{t+1}}^{\infty} V_{t+1}^{J}\left(a_{t+1}\right) \frac{f(a)}{1-F\left(\tilde{a}_{t+1}\right)} d a\right\}
$$

The marginal value of a match depends on real revenues minus the real wage plus the discounted continuation value. With probability $\left(1-\rho\left(\tilde{a}_{t+1}\right)\right)$ the job remains filled and earns the expected value and with probability, $\rho\left(\tilde{a}_{t+1}\right)$, the job is destroyed and has zero value. For each worker, the values of being employed and unemployed are given by $V_{t}^{E}$ and $V_{t}^{U}$ (expressed in terms of PPI):

$$
\begin{aligned}
& \left.V_{t}^{E}\left(a_{t}\right)=w_{t}\left(a_{t}\right) \phi_{t}+\beta E_{t}\left\{\left(\frac{\lambda_{t+1} / \phi_{t+1}}{\lambda_{t} / \phi_{t}}\right)\left[\left(1-\rho\left(\tilde{a}_{t+1}\right)\right) \int_{\tilde{a}_{t+1}}^{\infty} V_{t+1}^{E}\left(a_{t+1}\right) \frac{f(a)}{1-F\left(\tilde{a}_{t+1}\right)} d a+\rho\left(\tilde{a}_{t+1}\right) V_{t+1}^{U}\right]\right\}\right\}_{(26)} \\
& V_{t}^{U}=\phi_{t} b+ \\
& \beta E_{t}\left\{\left(\frac{\lambda_{t+1} / \phi_{t+1}}{\lambda_{t} / \phi_{t}}\right)\left[\theta_{t} q\left(\theta_{t}\right)\left(1-\rho\left(\tilde{a}_{t+1}\right)\right) \int_{\tilde{a}_{t+1}}^{\infty} V_{t+1}^{E}\left(a_{t+1}\right) \frac{f(a)}{1-F\left(\tilde{a}_{t+1}\right)} d a+\left(1-\theta_{t} q\left(\theta_{t}\right)\left(1-\rho\left(\tilde{a}_{t+1}\right)\right)\right) V_{t+1}^{U}\right]\right\}
\end{aligned}
$$

where $b$ denotes real unemployment benefits. The value of being employed depends on current wages and on the expected discounted future value function. With a probability $\left(1-\rho\left(\tilde{a}_{t+1}\right)\right.$ the match is preserved and the worker will stay into the employment pool, viceversa he will move to the unemployment pool. The value of being unemployed are given by the a monetary measure of unemployment benefit and non-market returns $b$, and by the expected discounted future value function. With a probability $\theta_{t} q\left(\theta_{t}\right)\left(1-\rho\left(\tilde{a}_{t+1}\right)\right)$ a match is formed and is continued into the next period so that the worker enters the employment pool and remains there for the subsequent period. The reverse is true in the alternative case.

Nash bargaining. Workers and firms are engaged in a Nash bargaining process to determine wages. The standard Nash bargaining problem is given by:

$$
\max _{w}\left(\left(V_{t}^{E}\left(a_{t}\right)-V_{t}^{U}\right)\right)^{\varsigma}\left(V_{t}^{J}\left(a_{t}\right)\right)^{1-\varsigma}
$$

where $\varsigma$ stands for the bargaining weight of the workers. After substituting the previously defined value functions in the optimal sharing rule $(1-\varsigma)\left(V_{t}^{E}\left(a_{t}\right)-V_{t}^{U}\right)=\varsigma V_{t}^{J}\left(a_{t}\right)$ it is possible to derive the following wage schedule:

$$
w_{t}\left(a_{t}\right)=\varsigma\left(m c_{t} z_{t} a_{t}+\theta_{t} \kappa\right) \frac{1}{\phi_{t}}+(1-\varsigma) b
$$

Importantly, it must be noticed that wages depend on the unemployment benefit and on a proxy of the terms of trade, $\phi_{t}$. Differential labor market and marginal cost dynamics, as determined by differences in labor market institutions, feed into terms of trade dynamic which in turn affect wages in the two economies. This is at the heart of the spillover effect between labor market dynamics and relative prices across countries. We will return on this point later on.

Total real wage is obtained by aggregating across employees: $w_{t}=\int_{\tilde{a}_{t}}^{\infty} w(a) \frac{f(a)}{1-F\left(\tilde{a}_{t}\right)} d a$. Equation (29) shows how the replacement rate affects the real wage which in turn has an impact on the threshold value of 
the idiosyncratic shock, as shown by equation (24), and on the marginal cost. From equation (23) indeed we can derive a measure of the marginal cost in our model which reads as follows:

$$
m c_{t}=\frac{1}{z_{t} H\left(\tilde{a}_{t}\right)}\left[\phi_{t} \frac{\partial W_{t}}{\partial n_{t}}+\mu_{t}-\frac{\kappa}{q\left(\theta_{t}\right)}\right]
$$

The first component of this measure is given by the marginal wage bargained divided by the labor productivity. This relation shows that the dynamic of the real wage has an impact on the dynamic of the marginal cost which in turn has an impact on the dynamic of inflation via equation (21). Another important feature to notice is that the measure of the marginal cost in this model, an contrary to the standard new keynesian model, depends on the cost of posting vacancies alongside with the worker marginal productivity (see Krause and Lubik (2005)). Firms attach an long run value to the worker as by maintaining the current match they can save on future costs of posting vacancies.

Real wage rigidity. As shown in Shimer (2005), Hall (2005) and Krause and Lubik (2005) introducing real wage rigidity improves the performance of the matching model in terms of the dynamic of labor market variables. We borrow from Hall (2005) and assume a simple form of wage rigidity which serves well our purposes. In particular we assume that the individual real wage is a weighted average of the one obtained through the Nash bargaining process and the one obtained as solution to the steady state ${ }^{20}$ :

$$
w_{t}(a)=\lambda\left[\varsigma\left(m c_{t} z_{t} a_{t}+\theta_{t} \kappa\right) \frac{1}{\phi_{t}}+(1-\varsigma) b\right]+(1-\lambda) w(a)
$$

As pointed out in Hall (2005), introducing wage rigidity into matching models allows to smooth wage volatility, which has been found too high in standard matching models relatively to empirical evidence (see Shimer (2005)), while reducing employment volatility. Overall wage rigidity should help improving the socalled employment volatility puzzle. Wage rigidity is also consistent with evidence on euro area countries as estimates by Smets and Wouters (2003) report a value for $\lambda$ on the magnitude of 0.6 . In this respect, wage rigidity allows the model to reproduce more closely the labor market characteristics of euro area economies. As for their relevance in terms of the dynamic results, the main mechanisms characterizing our models' dynamic remain unaltered in absence of wage rigidity.

\subsection{The Monetary Policy Rule in the Currency Area}

An active monetary policy sets the short term nominal interest rate by reacting to an average of the inflation levels in the area. This rule rationalizes the behavior of the stability pact signed by euro area countries:

$$
r_{t}^{n}=\exp \left(\frac{1-\chi}{\beta}\right)\left(r_{t-1}^{n}\right)^{\chi}\left(V_{H} \pi_{t}+V_{F} \pi_{t}^{*}\right)^{b_{\pi}(1-\chi)} m_{t}
$$

where $b_{\pi}$ is the weight that the monetary authority puts on the deviation of CPI inflation and is set equal to 1.5 and $m_{t}$ is a temporary monetary policy shock. $V_{H}$ and $V_{F}$ are the weights used to build up an aggregate measure of inflation for the currency area. In our benchmark analysis we will set $V_{H}=V_{F}=0.5$ but in the welfare analysis we will allow for different weights. In addition, following Clarida et al. (2000) and Rotemberg and Woodford (1997) we assume that monetary policy applies a certain degree $\chi$ of interest rate smoothing. Aside from being consistent with most evidence on monetary policy rules the interest rate smoothing helps to generate more persistent effect of monetary policy shocks.

${ }^{20}$ Hall (2005) proves that such a wage rule follows inside the range defined by the bargaining set. 


\subsection{Equilibrium Conditions}

Aggregate output is obtained by aggregating production of individual firms and by subtracting for the aggregate costs of posting vacancies:

$$
Y_{t}=n_{t} z_{t} \int_{\tilde{a}_{t}}^{\infty} a \frac{f(a)}{1-F\left(\tilde{a}_{t}\right)} d a-\kappa v_{t}
$$

After imposing market clearing, aggregating and recalling that $p_{h, t}=p_{h, t}^{*}$, we can express the resource constraint as:

$$
n_{t} z_{t} \int_{\tilde{a}_{t}}^{\infty} a_{t} \frac{f(a)}{1-F\left(\tilde{a}_{t}\right)} d a-\kappa v_{t}=\left(\frac{p_{h, t}}{p_{t}}\right)^{-\eta}(1-\gamma) c_{t}+\left(\frac{p_{h, t}}{p_{t}^{*}}\right)^{-\eta} \gamma^{*} c_{t}^{*}+\frac{\psi}{2}\left(\frac{p_{h, t}}{p_{h, t-1}}-1\right)^{2} y_{t}
$$

We assume zero total net supply of bonds.

\subsection{Calibration}

Preferences. Time is taken as quarters. The discount factor $\beta$ i set to 0.99 , so that the annual interest rate is equal to 4 percent. The elasticity of substitution between domestic and foreign goods, $\eta$, is set equal to 1.5 as in Backus et al. (1992). The parameter on consumption in the utility function is set equal to 2 consistently with estimates by Smets and Wouters (2003). The value of $\gamma$ is set to 0.25 , a value compatible with data for European countries.

Production. Following Basu and Fernald (1997), the value added mark-up of prices over marginal cost is set to 0.2 . This generates a value for the price elasticity of demand $\varepsilon$ of 6 . The cost of adjusting prices $\psi$ is set to 100 to generate a slope of the log-linear Phillips curve equal to 0.10. This is compatible with the estimates by Benigno and López-Salido (2002) for France and Germany. Results are in any case robust to alternative parametrization of $\psi$.

Labor market frictions parameters. The matching technology is a homogenous of degree one function which is characterized by the parameter $\xi$. Consistently with estimates by Petrognolo and Pissarides (2001), this parameter to 0.5 . The probability of finding a worker when having opened a vacancy, $q(\theta)$, is set to 0.7, in line with the evidence reported in ECB (2002) and Weber (2000). The probability for a worker of finding a job, $\theta q(\theta)$, is set equal to 0.6 , which implies an average duration of unemployment of 1.67 as reported in Cole and Rogerson (1999). With those values it is possible to determine the number of vacancies as well as the vacancy/unemployment ratio. The exogenous separation probability, $\rho^{x}$, is set to 0.06 consistently with evidence presented in Honijn and Sahin (2007). The steady state overall separation rate, $\rho(\tilde{a})$, is set to 0.15 . With those values it is possible to obtain the endogenous separation rate, $\rho^{n}(\tilde{a})=\frac{\rho(\tilde{a})-\rho^{x}}{1-\rho^{x}}$, and the threshold value, $\tilde{a}=F^{-1}\left(\rho^{n}\right)$. The idiosyncratic shock is distributed as a lognormal with unitary mean and standard deviation equal to 0.20 . Finally we set the degree of wage rigidity $\lambda$ equal to 0.3 as benchmark value and the steady state unemployment rate to $9 \%$, consistently with European data.

Labor market institutions. As in Krause and Lubik (2005), the unemployment benefit is obtained as solution to the steady state. In particular, we assign values for the bargaining power $\varsigma$, we then compute the unemployment benefit parameter $b$ from the steady state job destruction equation so as to generate values for the $\frac{b}{w}$ ratio which are in the range of the ones reported in table 1 . We will return on this point in the next section devoted to steady state analysis.

Exogenous shocks and monetary policy: We consider domestic and foreign aggregate productivity shocks, $z_{t}$ and $z_{t}^{*}$. We follow Backus et al. (1992) and calibrate their standard deviations to 0.008, their correlation to 0.258 and their persistence to 0.95 . We also consider an i.i.d. common monetary policy shock, $m_{t}$, whose standard deviation is calibrated using data from Mojon and Peersman (2003). Following several empirical studies for Europe (see Clarida et al. (2000), Angeloni and Dedola (1999) and Andrés et al. (2003) among others) we set the interest rate smoothing parameter $\chi$ equal to 0.8. Finally, we set $V_{H}=V_{F}=0.5$. 
Notice that we do not consider mark-up shocks even tough some empirical analysis like Smets and Wouters (2003) show that they might be important in driving inflation dynamics. We do so for two reasons. First, mark-up shocks might appear observationally equivalent to endogenous labor or product market wedges (see Chari et al. (2007)): as our model features an important labor market wedge we do not need to add extra sources of mark-up variations. Second, we employ only two basic demand and supply shocks as we aim to follow a conservative approach and show how much of the inflation dynamic is driven by labor market frictions without relying on any additional exogenous source of fluctuations that might bias results in our favor. Needless to say the mechanisms presented in the next sections are robust to alternative shocks as they are driven solely by the labor market characteristics.

\subsection{Steady State Analysis}

To better understand the role of replacement rates in our model it is worth analyzing the steady state equilibrium. Given all our exogenous parameters we solve the steady state by following the procedure indicated in Pissarides (2000) (chapter 2) ${ }^{21}$. In presence of endogenous job destruction the unemployment benefit, $b$, is a fixed proportion of the mean wage rate observed in the market according to the following relation:

$$
b=B R R w(a)
$$

where $B R R$ is the replacement rate. This implies that the value of $b$ is in fact determined endogenously in the model once $B R R$ is fixed. We solve jointly for the values of $b$ and $\kappa$ using the steady state versions of the labor market tightness and of the optimal productivity threshold. The solution to this system delivers two relations for $b$ and $\kappa$ which are function of exogenous parameters and steady state values. We implement our calibration exercise using data for $B R R$ and by adding the extra constraint represented by equation (34) to the equilibrium relations characterizing the steady state. To replicate the range of values found in the data for the variable $B R R$ we assign values to the bargaining power that allow us to replicate the desired ratio $\frac{b}{w}$.

Given our baseline parametrization for the remaining parameters it can be shown that a negative relation exists between the replacement rate and the bargaining power ${ }^{22}$. Intuitively this implies that countries with higher protection of incumbent workers devote less resources to protection of searching workers and viceversa. Unfortunately, while there is a direct measure in the data for the replacement ratio, this is not the case for the bargaining power. This is exactly the reason why we decided to focus our study on BRR. Variables like the employment protection legislation (EPL) and the union density (which we reported in table 1 and used in our empirical analysis as control variables) can be considered a broad measure of protection of incumbent workers but do not coincide with the bargaining power of the model. For example EPL also depends on firing costs. And a low union density does not necessarily mean low bargaining power because what matters is the union coverage. For example Italy has a relatively low union density but contracts are then extended to both unionized and non-unionized workers.

\section{Quantitative Properties of the Model}

In this section we analyze the main quantitative properties of the model and the impulse response functions of the main variables. We have two goals in mind. First, we want to validate the model, showing that it mimics well the main business cycle properties of the euro area economy. Second, we calculate impulse responses to provide a first assessment on how different values of the replacement rate generate different responses of wages, marginal costs, and inflation, to better understand the structural links among these variables. Having done this, the next section will be devoted to assess whether the model can replicate the stylized facts shown earlier.

\footnotetext{
${ }^{21}$ The same procedure is followed by several other authors such as Krause and Lubik (2005), Walsh (2003).

${ }^{22}$ Figures are not reported for brevity but are available upon request.
} 
Table 2 shows standard deviations of selected variables (relative to output) for euro area data ${ }^{23}$ and for the model economy. In this case our calibration for the replacement rate is the average value across euro area countries. Standard deviations for the model have been computed by simulating the model 100 times for 200 periods and calculations are based on Hodrick-Prescott filtered series. As customary in the real business cycle literature, we simulate both technology and common monetary policy shocks, all of which are calibrated on euro area data (see calibration section). In computing the statistics for this table we assumed complete symmetry between the two countries for all parameters, including those of the labor market in the next section instead we will allow these parameters to vary to show their impact on the relevant volatilities. This implies that the sizes of the standard deviations for the home and the foreign countries are very similar ${ }^{24}$. The first thing to be noticed is that output in the model is more volatile then output in the data. It is important to bear in mind that output volatility has been particularly low in the last 10 years, a phenomenon usually refer to as great moderation. Even though the reduction in output volatility has been well documented, the debate on the sources of such moderation is still open. In the present paper we neither try to explain nor to match the great moderation thus, the higher volatility of output in the model. When comparing the volatility of consumption, inflation and employment (all relative to output volatility) we can see that the model does a good job in matching the data ${ }^{25}$. Another way to assess the quantitative properties of our model economy concerns the model ability to replicate the international co-movements. It is well-known that output and employment are positively correlated across countries (see Backus et al. (1992) and Faia (2007) ). Our simulations (with both productivity and monetary policy shocks) show that our model economy generates a correlation between home and foreign output of 0.87 and a correlation between home and foreign employment of 0.91 .

Impulse response analysis is now used to provide a first assessment of the differential impact of different replacement rates on the two countries dynamics. The model is calibrated so that the home country has a smaller replacement rate than the foreign country, while in all the other parameters the two countries are symmetric. In particular the replacement ratio for the home and the foreign country are set to 0.35 and 0.84 respectively.

Figure 3 reports the impulse response functions of domestic variables to domestic (positive) technology shock (solid line in each panel) and of foreign variables to a foreign (positive) technology shocks (dashed line in each panel).

By plotting in the same panels impulse responses to shocks of the same size we can appreciate the impact of different replacement rates across countries. Let's start to analyze the impulse responses of domestic variables to a domestic productivity shock. On impact, as we can see from figure (3), domestic output rises but domestic unemployment rises and wages fall. The increase in unemployment is due mainly to the assumption of price rigidity (see Galí (2003) ${ }^{26}$. In the subsequent periods prices can fully adjust hence unemployment falls below its steady state level. Real marginal cost decreases because of both the higher productivity and the lower real wages. This mechanism would be observable also in a closed economy but in an open economy framework it is amplified by the terms of trade effect. Because of the domestic technology improvement domestic goods become cheaper than foreign ones hence domestic exports and demand increase.

Let's now analyze the dynamic of foreign variables in response to a foreign productivity shock. Since the foreign country has a higher replacement rate this comparison can reveal the role played by replacement

\footnotetext{
${ }^{23}$ Standard deviations of euro area data are computed over the period 1998-2007 using data from the Area Wide Model available at www.eabcn.org. The original series have been filtered with Hodrick-Prescott filter.

${ }^{24}$ Although not the same since the productivity shocks have a correlation of 0.25 .

${ }^{25}$ Unfortunately it is not possible to calculate empirical standard deviations for vacancies and labor market tightness since it is not possible to find long enough series for euro area countries. The model standard deviations are somewhat lower than the ones calculated by Krause and Lubik (2005) for the U.S. (8.27 for vacancies and of 14.96 for labor market tightness).

${ }^{26}$ Due to price rigidity, firms in the first period will not reduce the prices as they would have done without adjustment costs. Therefore, aggregate demand increases by less than in the flexible price case. Since the productivity increase allows to produce the same amount with less work this leads to lower employment and real wages.
} 
rates. As already noted, unemployment rises and wages decline in both countries after a positive technology shock. Since in the home country domestic workers face a lower replacement rate, they also face worst outside option, which expands (steady state) wages and compresses (steady state) profits. The opposite is true for the foreign country. Because of this and given an equal seized productivity shock in the two economies, foreign firms experience a higher percentage change in profits than domestic firms. This increases foreign firms' incentives to post vacancies. At the same time, foreign wages change by less in percentage terms, because they are already relatively large in absolute terms in the steady state. This bears out in the falling volatility of foreign real marginal costs and inflation.

Figure 4 shows the dynamic of home and foreign variables after a monetary policy tightening. In our setting (currency union, same transmission mechanisms), this is a perfectly symmetric demand shock. Output and employment contract in both countries. However domestic wages, marginal costs and inflation fall below the foreign ones. This is because domestic workers face lower replacement rates, hence worst outside options in case of unemployment. This implies that in response to the monetary shock the percentage change of domestic wages is higher compared to this of foreign ones. The higher volatility in domestic wages induces also higher volatility in marginal costs and inflation.

In general we can conclude that under both demand and supply shocks real wages, marginal cost and inflation are more sensitive for countries with lower replacement rates. It is worth noticing that the size of the differentials we obtain from the impulse responses is lower in terms of magnitude than the one observed in the data: this is so since impulse response functions show by construction the response to only one shock at the time. The next paragraph is devoted to show how the model can match the size of the differentials in response to several shocks.

\subsection{Matching the Data}

The data matching exercise is conducted by showing that the model can reproduce the relationship found in the data between ratios of volatilities (of real wages and inflation) and ratios of replacement rates across pairs of countries. The reason why we do this instead of simply showing the relationship between replacement rate levels and volatility levels for an individual country is that, when changing the value of the replacement rate in (say) the foreign country, the equilibrium volatilities change both at home and abroad, even if the replacement rate at home remains unchanged. The volatility spillover is stronger if the two economies are closely interconnected, as is the case in EMU. Hence, in order to correctly match the extent to which differences in labor market structures generate differences in volatility for our two variables, we need to be able to approximate well the interpolating curves shown in figure 2 .

Figure 5 shows the exponential interpolation curves (alongside with the linear ones) shown in figure 2 together with its model-based equivalents. Model-based standard deviations are computed using simulated series with length $T=200$ and calculations are based on the Hodrick-Prescott filtered series. The model is simulated under both technology and monetary policy shocks calibrated on euro area data, as described earlier. Considering both shocks allows us to account for the closest possible match between the data and the model. The range of variation for the ratio of the replacement rates is calibrated so as to match the value reported in table 1 . More precisely, $\left(b^{*} / w^{*}\right)$ for the foreign country is set to 0.86 , then $b / w$ for the home country takes values ranging between 0.84 and 0.35 . The model is then simulated for each pair $\left[b / w,\left(b^{*} / w^{*}\right)\right]$ to obtain the standard deviations for both countries. Following the procedure adopted to construct figure 2 , in figure 5 volatilities for foreign variables are always divided by the corresponding volatilities for the home variables. This makes the data and the model results comparable.

Figure 5 shows that the model is able to replicate the negative relations found in the data for both variables, thereby confirming our mechanism. Interestingly the model-based relations are non-linear and convex with respect to the origin, as our exponential interpolations. The shapes of the theoretical curves broadly (though not perfectly, as one would expect) match the empirical ones ${ }^{27}$.

\footnotetext{
${ }^{27}$ The model generates a negative relation also between absolute levels of real wages and inflation on the one side and the
} 
The mechanism explaining the negative relation between replacement rates and volatility of wages in our model resembles the one featured in Hagedorn and Manovskii (2008). Those authors have shown that a closed economy model with search and matching frictions can generate high volatilities of unemployment and low volatilities of wages, as observed in the data, if one uses a calibration with high values of unemployment benefits and low values of bargaining power. Specifically they stress that high values of replacement rates can dampen wage fluctuations as they dampen the response of wages to productivity shocks. The reason for this is as follows. An increase in the replacement rates has two effects: on the one side, it increases steady state wages and decreases the response of wages to shocks; on the other side, it compresses steady state profits and amplifies the response of profits and labour market tightness to shocks. Since wages, depend on both, unemployment benefits and labour market tightness, the second effect might in principle overcome the first and render wages equally sensitive to shocks, independently from the unemployment benefit. However, by assuming low values of bargaining power, wages become more dependent upon non-market activity and less dependent on labour market tightness. Under those circumstances an increase in the unemployment benefit results in lower wage volatility ${ }^{28}$. Our calibration strategy, as detailed in section 3.6 , follows the original calibration strategy presented in Mortensen and Pissarides (1999) model who find a one to one negative relation between unemployment benefits and bargaining power: based on this type of calibration high values of BRR in our model are associated with low values of bargaining power, hence they generate low cyclicality of wages. As stressed before, the difference in wage and inflation volatility across countries is generated by the difference in BRR but is amplified, compared to a closed economy model, by the movements in the terms of trade.

\subsection{Open Economy Spillovers and the Degree of Openness}

So far results have shown that national labor market institutions have an impact on inflation and price dynamic, which in turn affect the dynamic of terms of trade. Additionally, the latter influences the wage equation in each of the two countries as shown by the equation (for the case of $\lambda$ equal to zero and for the domestic economy):

$$
w_{t}\left(a_{t}\right)=\varsigma\left(m c_{t} z_{t} a_{t}+\theta_{t} \kappa\right) \frac{1}{\phi_{t}}+(1-\varsigma) b
$$

For given replacement rate in the foreign country, a higher replacement rate in the home country has two effect. First it reduces wage and inflation volatility because of the above-mentioned mechanism. Second, the fall in domestic inflation reduces terms of trade volatility (for given correlation between domestic and foreign inflation) which in turn dampens further wage volatility. This is the sense in which the effects of national labor market structures tend to spillover toward foreign economies. In this context the relative degree of openness between the two countries, by affecting terms of trade volatility, also determines the amplitude of the spillover effect.

The degree of openness in our model is measured by the share of imports, $\gamma$, in the consumption index aggregator. A country with a bigger share of net exports over GDP will transmit more its own price dynamic as driven by labor market institutions. As euro area countries are characterized by moderate degrees of heterogeneity in trade openness, the relative share of net exports across countries might flatten or amplify the overall spillover effect from labor market dynamics to terms of trade.

For this reason it is worth to test whether the results presented in the previous section are robust to the assumption that countries are asymmetric in their degree of trade openness. We do so in figure 6 where we show the model based relations between standard deviations and replacement rates for the case in which countries have asymmetric degree of openness. We plot three different cases: the case of symmetric

levels of replacement rates on the other. However, the shape of the curve is not convex, but concave relative to the origin. Results are not reported for brevity but are available on request.

${ }^{28}$ Haefke et al. (2008) find the same type results (see line 25 of table 12, page 38) and argue in their introduction and conclusions that the Hagedorn and Manovskii (2008) calibration could be perfectly consistent with the data. 
countries with the baseline parametrization of $\gamma=\gamma^{*}=0.25$ and two cases of asymmetric countries in which we alternate the following parametrization $\gamma=0.2$ and $\gamma^{*}=0.4$ and $\gamma=0.4$ and $\gamma^{*}=0.2$. The range of cross-country variability considered for the parameter $\gamma$ is the maximum admissible given euro area data. Figure 6 shows that the relations remain practically the same.

\subsection{The Impact of Employment Protection}

To further assess the ability of our model to explain the link between labor market structures and the business cycle we repeated the analysis so far described by proxing labor market institutions through the indicator of employment protection. In our model this indicator is proxied by the worker bargaining power, $\varsigma$. As opposed to the replacement rate the indicator for employment protection is a less reliable measure of labor market characteristics for two reasons. First, it is based on workers and union strength indicators rather than on a straight monetary measure. Secondly, there are measurement comparability problems across countries. Despite this we believe testing our model along this additional dimension can help to sharpen further the analysis.

We found a positive relation between business cycle volatilities of real wages, marginal costs and inflations on the one side and the sizes of the bargaining power, $\varsigma$, on the other ${ }^{29}$. Intuitively an increase in the workers' bargaining power reduces both the value of the outside option for the workers (relatively to existing jobs) and the share of surplus accruing to the firm. Because of this firms productivity threshold increases therefore raising the mass of workers who are affected by the aggregate productivity. This reduces the volatility of unemployment and raises that of wages.

As explained in the section devoted to steady state analysis, data for the EMU countries show an inverse relation between employment protection and replacement rates exactly as in the steady state of the model. This implies a positive, thought not significant, relation between business cycle responses of real wages and inflations on the one side and the employment protection on the other as it can be seen from tables 3 and 4. We believe these results to be important given the somehow loose link between the bargaining power and EPL.

Overall our results point out at another interesting dimension of the mechanism featured by our model and confirmed by the data. In our context a country experiences high volatility of wages and inflation if it is characterized by low replacement rates, which implies high protection of incumbent workers and low protection of searching workers. As shown in table 1, Mediterranean countries (Italy, Spain and Portugal) cluster by showing low replacement rates and high protection of incumbent workers. For those countries in fact wages are more sensitive to shocks, but job flows are highly sclerotic as firms tend to hire less workers while adjusting over-hours and wages.

\section{Welfare Analysis}

The analysis conducted in the previous paragraphs should have convinced the reader about our main claim i.e., structural differences in labour market institutions across European countries are a source of inflation volatility differentials. A natural question to ask then, is whether those volatility differentials are enough to generate sizable welfare losses. Given that we do not correct for steady state distortions in the model, we resort to a numerical second order approximation of both the utility function and all the equilibrium conditions following Schmitt-Grohe and Uribe (2004). Let $\left\{C_{t}^{s}\right\}_{t=0}^{\infty}$ and $W_{0}^{s}$ be respectively the sequence of consumptions and the conditional welfare for the case in which the two countries share the same labour market structure and $\left\{C_{t}^{a}\right\}_{t=0}^{\infty}$ and $W_{0}^{a}$ be the ones for the asymmetric case. Define $\omega$ to be the fraction of household's consumption needed to equate the two conditional welfare i.e.,

\footnotetext{
${ }^{29}$ Results are not reported for brevity but are available upon request.
} 


$$
E_{0}\left\{\sum_{t=0}^{\infty} \beta^{t} \frac{\left[(1+\omega) C_{t}^{a}\right]^{1-\sigma}}{1-\sigma}\right\}=E_{0}\left\{\sum_{t=0}^{\infty} \beta^{t} \frac{\left(C_{t}^{s}\right)^{1-\sigma}}{1-\sigma}\right\} \equiv W_{0}^{s}
$$

Then it is possible to show that, under this specification of the utility function,

$$
\omega=\frac{W_{0}^{s}+[(1-\beta)(1-\sigma)]^{-1}}{W_{0}^{a}+[(1-\beta)(1-\sigma)]^{-1}}-1
$$

The results are reported in table 7 . First, we compute the conditional welfare for each country and for the world economy for the case in which the two countries are perfectly symmetric, even for what concern the labour market structure ${ }^{30}$. Then, we compute the conditional welfare for the case in which the labour market structure is asymmetric ${ }^{31}$. Conditional welfare decreases for both countries with different labour market structures. As usual in this literature, we compute the (\%) welfare losses in terms of steady state consumption. The numbers reported in the last column shows that differences in labour market institutions lead to sizable welfare losses bot for each country and for the currency area as a whole. We disentangle the effects that induce welfare losses as follows. First, changes in the replacement rate lead to changes in the long run level of wages: the latter indeed increase above the walrasian level for the country with the lower replacement rate (higher bargaining power) and below the walrasian level for the country with the higher replacement rate (lower bargaining power). In this respect both countries feature an inefficient adjustment in the labour market. Second, increasing the differences in the replacement rate leads to increasing differences in the dynamic of inflation across countries. This brings about an increase in the volatility of terms of trade. Recall that terms of trade represent a wedge themselves as they enter the labour market equilibrium condition, therefore distort the allocation of employment across countries. An increase in terms of trade fluctuations increases the extent of such area wide inefficiencies.

We also repeat the exercise allowing for different weights in the monetary policy rule to see whether monetary policy can cope with such differences in efficiency. In particular we consider the case in which the monetary authority gives higher weight to the inflation rate of the country with lower replacement rate (home). This seems a reasonable assumption given that, when the two countries are asymmetric, that will be the country with the more volatile inflation. Even thought this seems to imp[rove on the previous scenario, welfare losses due to asymmetric countries are only marginally reduced.

\section{Conclusions}

In this paper we study the role of labor market differences in generating differential inflation volatility among euro area countries. To do this we use a stylized DSGE model where labor market frictions are an important determinant of the dynamics of marginal costs of firms, which in turn are a main driver of inflation. We find that differences in labor market institutions (proxied by the replacement rates, or alternatively by a measure of workers' bargaining power) can generate significant volatility differentials in real wages, marginal costs for firms and inflation when the model is subject to a variety of realistic shocks. Those volatility differentials generate important welfare losses. The volatilities of the three aforementioned variables tend to be higher when the unemployed is less protected (low replacement rate) or the employed is more protected (high bargaining power). The link between labor market institutions and volatilities embodied in our model approximates well the one observed in the data.

\footnotetext{
${ }^{30}$ We set $b / w=(b / w)^{*}=0.66$. All the other parameters are calibrated according to section 3.5 .

${ }^{31}$ We do so by lowering the replacement ratio of the home country from 0.66 to 0.38 and by increasing the replacement ratio of the foreign country from 0.66 to 0.75 .
} 


\section{References}

Andolfatto, D., 1996. Business cycles and labor market search. American Economic Review 86 (1), $112-132$.

Andrés, J., Ortega, E., Vallés, J., 2003. Market structure and inflation differentials in the european monetary union. Banco de España Working Papers (301).

Angeloni, I., Dedola, L., 1999. From the ERM to the EURO: New evidence on economic and policy convergence among EU countries. ECB Working Paper (4).

Angeloni, I., Ehrmann, M., 2007. Euro area inflation differentials. The Berkeley Electronic Journal of Macroeconomics 7 (1).

Backus, D. K., Kehoe, P. J., Kydland, F. E., 1992. International real business cycles. Journal of Political Economy 100, 745-775.

Basu, S., Fernald, J. G., 1997. Returns to scale in u.s. production: Estimates and implications. Journal of Political Economy 105 (2), 249-283.

Benigno, P., López-Salido, J. D., 2002. Inflation persistence and optimal monetary policy in the EURO area. European Central Bank working papers (178).

Blanchard, O. J., Galí, J., 2007. The macroeconomic effects of oil price shocks: Why are the 2000s so different from the 1970s? NBER Working Paper 13368.

Blanchard, O. J., Wolfers, J., 2000. The role of shocks and institutions in the rise of european unemployment: The aggregate evidence. The Economic Journal 110, 1-33.

Chari, V., Kehoe, P., McGrattan, E., 2007. Business cycle accounting. Econometrica 75, 781-836.

Clarida, R., Galí, J., Gertler, M., 2000. Monetary policy rules and macroeconomic stability: Evidence and some theory. Quarterly Journal of Economics 115 (1), 147-180.

Cole, H. J., Rogerson, R., 1999. Can the mortensen-pissarides matching model match the business-cycle facts? International Economic Review 4 (4), 933-959.

Cooley, T. F., Quadrini, V., 1999. A neoclassical model of the phillips curve relation. Journal of Monetary Economics 44, 165-193.

Costain, J. S., Reiter, M., 2008. Business cycles, unemployment insurance, and the calibration of matching models. Journal of Economic Dynamics and Control 32, 1120-1155.

ECB, 2002. Labour market mismatches in the euro area countries. European Central Bank.

ECB, 2003. Inflation differentials in the euro area: Potential causes and policy implications. European Central Bank Technical Report.

Faia, E., 2007. Finance and international business cycle. Journal of Monetary Economics 54 (5).

Faia, E., 2008. Optimal monetary policy rules with labour market frictions. Journal of Economic Dynamics and Control 32 (5), $1600-1621$.

Galí, J., 2003. New perspectives on the monetary policy, inflation, and the business cycle. Advances in Economic Theory vol. III, $151-197$.

Haefke, C., Sonntag, M., van Rens, T., 2008. Wage rigidity and job creation. IZA Discussion Paper Series 3714.

Hagedorn, M., Manovskii, I., 2008. The cyclical behavior of equilibrium unemployment and vacancies revisited. American Economic Review.

Hall, R. E., 2005. Employment fluctuations with equilibrium wage stickiness. American Economic Review 95 (1).

Honijn, B., Sahin, A., 2007. Job-finding and separation rates in the oecd. Federal Reserve Bank of New York 298.

Honohan, P., Lane, P., 2003. Divergent inflation rates in EMU. Economic Policy 18 (37), 357 - 394.

Krause, M. U., Lubik, T. A., 2005. The (ir)relevance of real wage rigidity in the new keynesian model with search frictions. Journal of Monetary Economics, Forthcoming.

Merz, M., 1995. Search in the labor market and the real business cycle. Journal of Monetary Economics $36,269-300$.

Mojon, B., Peersman, G., 2003. A VAR description of the effects of monetary policy in the individual countries of the euro area. Monetary Policy Transmission in the Euro Area.

Mortensen, D., Pissarides, C., 1999. New developments in models of search in the labor market. Handbook of Labor Economics. Edited by Ashenfelter, O.; Card, D. North-Holland.

Nickell, S., 1997. Unemployment and labour market rigidities: Europe versus north america. Journal of Economic Perspectives $11,55-74$.

Nickell, S., Nunziata, L., 2007. Labour market institutions database.

Petrognolo, B., Pissarides, C., 2001. Looking into the black box: A survey of the matching function. Journal of Economic Literature 39 (2), 390-431.

Pissarides, C., 2000. Equilibrium Unemployment Theory. MIT Press.

Rotemberg, J., Woodford, M., 1997. An optimization-based econometric framework for the evaluation of monetary policy. NBER Macroeconomics Annual 12, 297-346.

Rotemberg, J. J., 1982. Sticky prices in the united states. The Journal of Political Economy 90 (6), $1187-1211$.

Sapir, A., 2006. Globalisation and the reform of european social models. Journal of Common Market Studies.

Schmitt-Grohe, S., Uribe, M., 2004. Solving dynamic general equilibrium model using a second-order approximation to the policy function. Journal of Economic Dynamics and Control 28 (4), 755-775.

Shimer, R., 2005. The cyclical behavior of equilibrium unemployment and vacancies. American Economic Review 95 (1), $25-49$.

Smets, F., Wouters, R., 2003. An estimated dynamic stochastic general equilibrium model of the euro area. Journal of European Economic Association 1, 1123-1175.

Thomas, C., 2008. Search and matching frictions and optimal monetary policy. Journal of Monetary Economics. 
Walsh, C., 2003. Labor market search and monetary shocks. In: Altug, S., Chadha, J., Nolan, C. (Eds.), Elements of Dynamic Macroeconomic Analysis. Cambridge University Press, pp. $451-486$.

Weber, A., 2000. Vacancy durations - a model for employer's search. Applied Economics 32, 1069-1075.

Zanetti, F., 2007. Labor market institutions and aggregate fluctuations in a search and matching model. Bank of England, mimeo. 
Table 1: Labour Market Variables. For the measures of replacement rates (benefit as a ratio to average earnings before taxes computed by Nickell and Nunziata) we use the value at 2004. For the two measures of Employment Protection Legislation (taken from OECD Employment Outlook, 2004) the latest available data refer to 2003. For the Union Density (also taken from OECD) we use the value at 2004 .

\begin{tabular}{lcccc} 
Countries & Replacement rate & EPL1 & EPL2 & UD \\
\hline \hline Austria & 0.82 & 1.9 & 2.2 & 34.1 \\
Belgium & 0.60 & 2.2 & 2.5 & 52.9 \\
Finland & 0.51 & 2.0 & 2.1 & 73.3 \\
France & 0.52 & 3.0 & 2.9 & 8.0 \\
Germany & 0.60 & 2.2 & 2.5 & 22.2 \\
Ireland & 0.86 & 1.1 & 1.3 & 35.7 \\
Italy & 0.34 & 1.9 & 2.4 & 33.9 \\
Netherlands & 0.74 & 2.1 & 2.3 & 21.3 \\
Portugal & 0.46 & 3.5 & 3.5 & 18.7 \\
Spain & 0.30 & 3.1 & 3.1 & 15.5 \\
\hline
\end{tabular}

Table 2: Business cycle properties of the euro area economy and of the model economy.Statistics for the euro area are computed over the period 1998:01 - 2007:04 using the data from the AREA Wide Model available from www.eabcn.org. Statistics from the model are Hodrick-Prescott filtered and are computed under two correlated productivity shocks and one common monetary policy shock. All standard deviations are relative to output.

\begin{tabular}{llll} 
& Euro area & Model economy & \\
\hline \hline Standard deviation & & Home country & Foreign country \\
\hline Output & 0.7585 & 1.9407 & 1.9423 \\
Consumption & 0.7299 & 0.9684 & 0.9678 \\
Inflation (GDP deflator) & 0.2532 & 0.2776 & 0.2755 \\
Employment & 0.9576 & 1.1077 & 1.1042 \\
Vacancies & $\ldots$ & 2.8330 & 2.8132 \\
Tightness & $\ldots$ & 8.4237 & 8.4056 \\
\hline
\end{tabular}

Table 3: Linear Regressions for Inflation Volatility. For each variable the estimated coefficient and the t-statistic are reported. Volatilities have been computed over the period 1998-200\%.

\begin{tabular}{cccccc} 
Variables & $y=a * x^{b}$ & $(1)$ & $(2)$ & $(3)$ & $(4)$ \\
\hline \hline Constant & 0.2187 & 1.1829 & 0.9799 & 0.9344 & 1.2155 \\
& $(-6.5912)$ & $(4.6671)$ & $(1.7178)$ & $(1.2631)$ & $(4.2303)$ \\
Replacement Rate & -1.1601 & -1.2211 & -1.1203 & -1.1164 & -1.2040 \\
& $(-3.6239)$ & $(-2.7318)$ & $(-2.0832)$ & $(-1.9982)$ & $(-2.5044)$ \\
EPL1 & & 0.0609 & & \\
& & $(0.4042)$ & & 0.0734 & \\
EPL2 & & & $(0.3610)$ & -0.0013 \\
UD & & & & $(-0.3423)$ \\
\hline R square & 0.6523 & 0.5160 & 0.5288 & 0.5263 & 0.5253
\end{tabular}


Table 4: Linear Regressions for Wage Volatility. For each variable the estimated coefficient and the t-statistic are reported. Volatilities have been computed over the period 1998-2006.

\begin{tabular}{cccccc} 
Variables & $y=a * x^{b}$ & $(1)$ & $(2)$ & $(3)$ & $(4)$ \\
\hline \hline \multirow{2}{*}{ Constant } & 0.4148 & 2.1871 & 0.4964 & 0.6817 & 2.4175 \\
& $(-3.3491)$ & $(3.3342)$ & $(0.3106)$ & $(0.3158)$ & $(3.2727)$ \\
Replacement Rate & -1.0487 & -2.1933 & -1.1856 & -1.3805 & -2.1245 \\
& $(-2.6909)$ & $(-2.0617)$ & $(-0.8737)$ & $(-0.8846)$ & $(-1.9322)$ \\
EPL1 & & 0.5064 & & \\
& & $(1.1549)$ & & 0.4339 & \\
EPL2 & & & $(0.7347)$ & \\
& & & & -0.0082 \\
UD & & & & $-0.7721)$ \\
\hline R square & 0.5085 & 0.3778 & 0.4910 & 0.4292 & 0.4340
\end{tabular}

Table 5: Ratios of Inflation Volatilities Vs Ratios of Benefits. For each variable the estimated coefficient and the t-statistic are reported. Volatilities have been computed over the period 1998-200\%.

\begin{tabular}{cccccc} 
Variables & $y=a * x^{b}$ & $(1)$ & $(2)$ & $(3)$ & $(4)$ \\
\hline \hline Constant & 1.0527 & 1.4735 & 2.3026 & 2.8815 & 1.3803 \\
& $(0.3325)$ & $(4.7148)$ & $(5.7835)$ & $(6.5093)$ & $(4.2262)$ \\
Ratios Replacement Rate & -0.8053 & -0.3639 & -0.4908 & -0.5833 & -0.3685 \\
Ratios EPL1 & $(-2.5322)$ & $(-1.8889)$ & $(-2.6991)$ & $(-3.3399)$ & $(-1.9111)$ \\
Ratios EPL2 & & -0.7565 & & \\
Ratios UD & & $(-3.0036)$ & & -1.2770 & $(-4.0050)$ \\
R square & & & & 0.0608 \\
& & & & & $0.9862)$ \\
\hline
\end{tabular}


Table 6: Ratios of Wage Volatilities Vs Ratios of Benefits. For each variable the estimated coefficient and the $t$-statistic are reported. Volatilities have been computed over the period 1998-2006.

\begin{tabular}{cccccc} 
Variables & $y=a * x^{b}$ & $(1)$ & $(2)$ & $(3)$ & $(4)$ \\
\hline \hline Constant & 0.9989 & 1.2913 & 0.8947 & 1.0283 & 1.3683 \\
& $(-0.0066)$ & $(6.4794)$ & $(3.0877)$ & $(2.8318)$ & $(6.6898)$ \\
Ratios Replacement Rate & -1.0470 & -0.3417 & -0.2863 & -0.3022 & -0.3352 \\
& $(-3.2725)$ & $(-2.8460)$ & $(-2.3861)$ & $(-2.3456)$ & $(-2.8263)$ \\
Ratios EPL1 & & 0.3704 & & \\
Ratios EPL2 & & $(1.8331)$ & & 0.2366 & \\
Ratios UD & & & & $(0.8679)$ & -0.0531 \\
& & & & & $(-1.3757)$ \\
\hline R square & 0.2395 & 0.1924 & 0.2670 & 0.2104 & 0.2362
\end{tabular}

Table 7: Conditional Welfare. For the symmetric case we assume $b / w=(b / w)^{*}=0.66$. For the asymmetric case we set $b / w=0.38$ and $(b / w)^{*}=0.75$. For each case we report the conditional welfare of each country and of the world economy. In the last column we report the welfare losses of moving from a symmetric situation to a case where labour market institutions differ across the two countries. Welfare losses are expressed in terms of (\%) steady state consumption.

Symmetric Countries Asymmetric Countries (\%) Welfare Losses

\begin{tabular}{cllllll} 
& Symmetric Countries & Asymmetric Countries & (\%) Welfare Losses \\
\hline \hline \multirow{2}{*}{$\begin{array}{c}\text { Taylor Rule with } \\
\text { equal weights }\end{array}$} & Fome & 108.3821 & Home & 108.1282 & Home & -3.0291 \\
& World & 108.3575 & Foreign & 108.2747 & Foreign & -0.9907 \\
& & & & & & \\
& Home & 108.3863 & Home & 108.1334 & Home & -3.0156 \\
Taylor Rule with & Foreign & 108.3603 & Foreign & 108.2784 & Foreign & -0.9796 \\
vH $=0.8, \mathrm{vF}=0.2$ & World & 216.7467 & World & 216.4118 & World & -0.2869 \\
& & & & & & \\
\hline
\end{tabular}



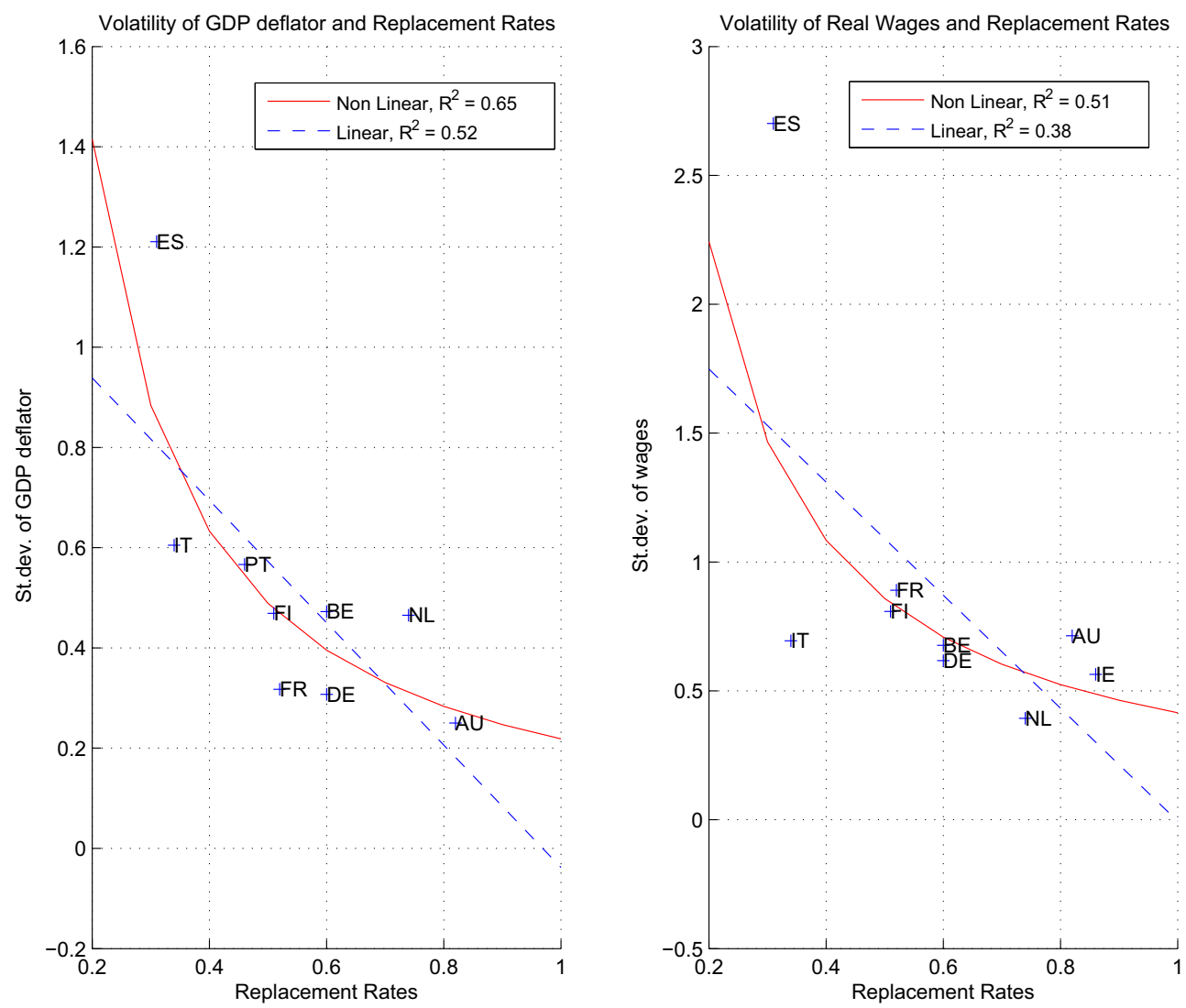

Figure 1: Relation between standard deviation of wages and inflation (relative to that of output) and replacement rates for the EMU countries 

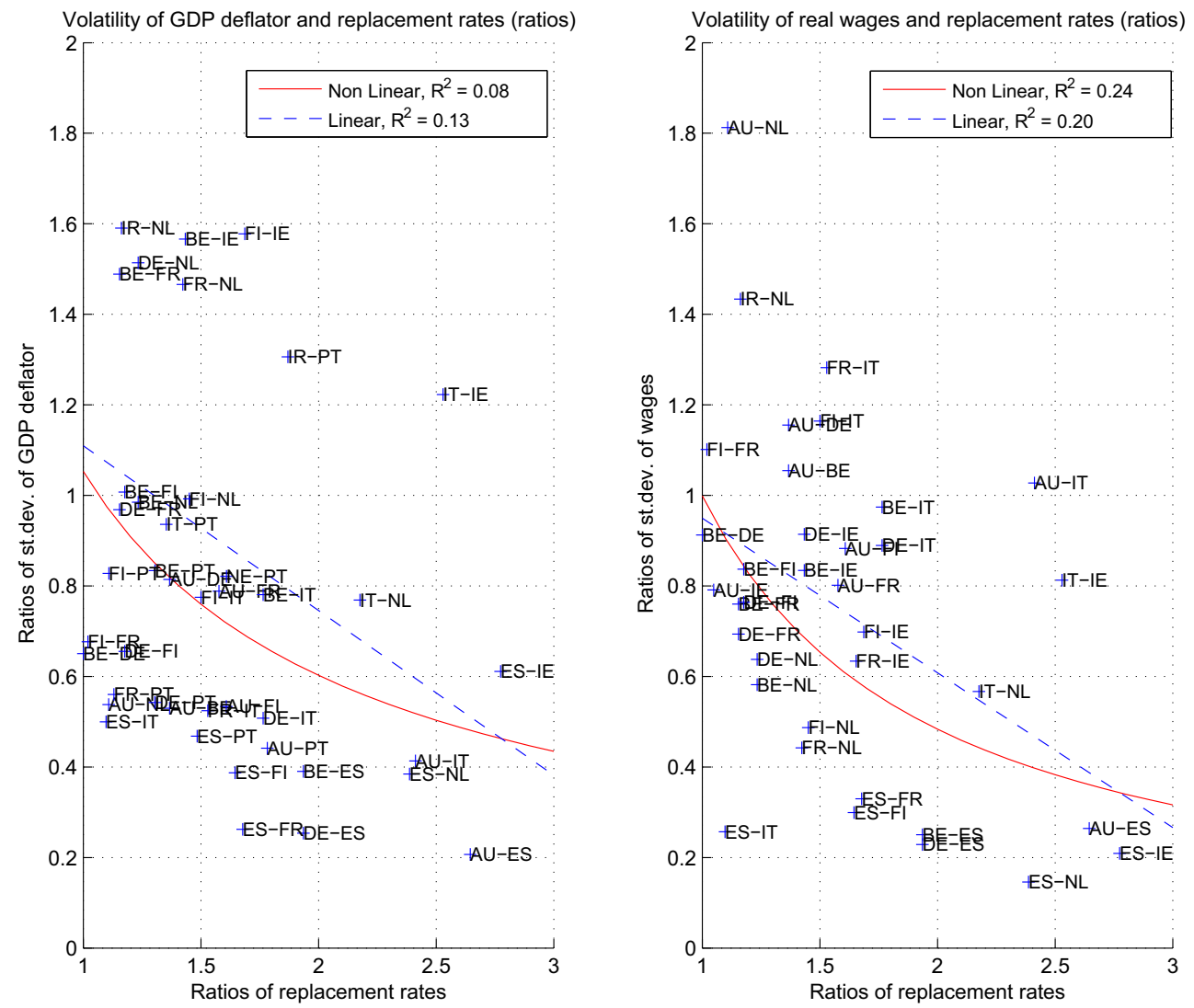

Figure 2: Relation between ratios of standard deviation of wages and inflation (relative to that of output) and ratios of replacement rates for the EMU countries 

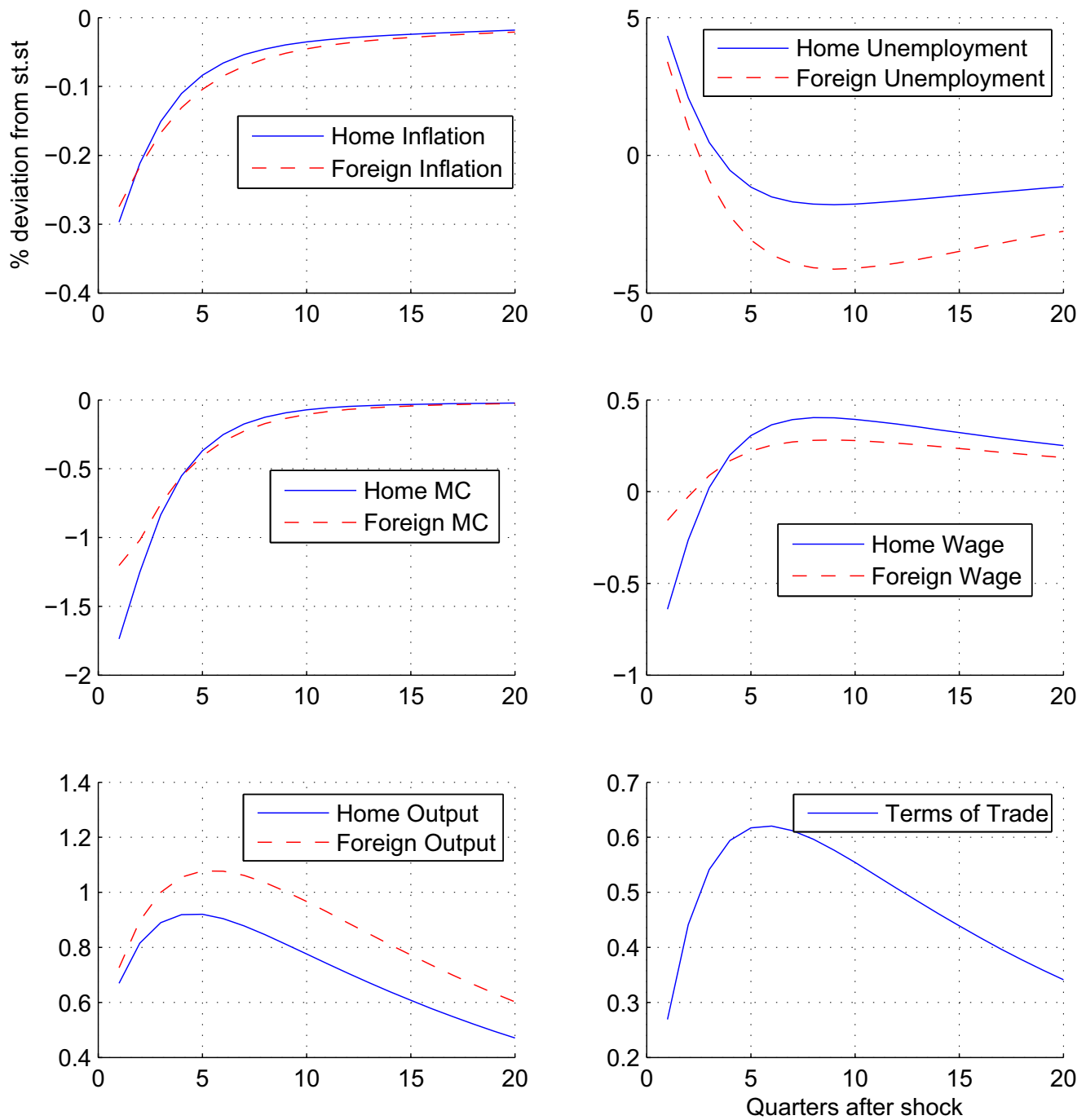

Figure 3: Impulse responses of selected domestic and foreign variables to domestic (solid line) and foreign technology (dashed line) shocks 

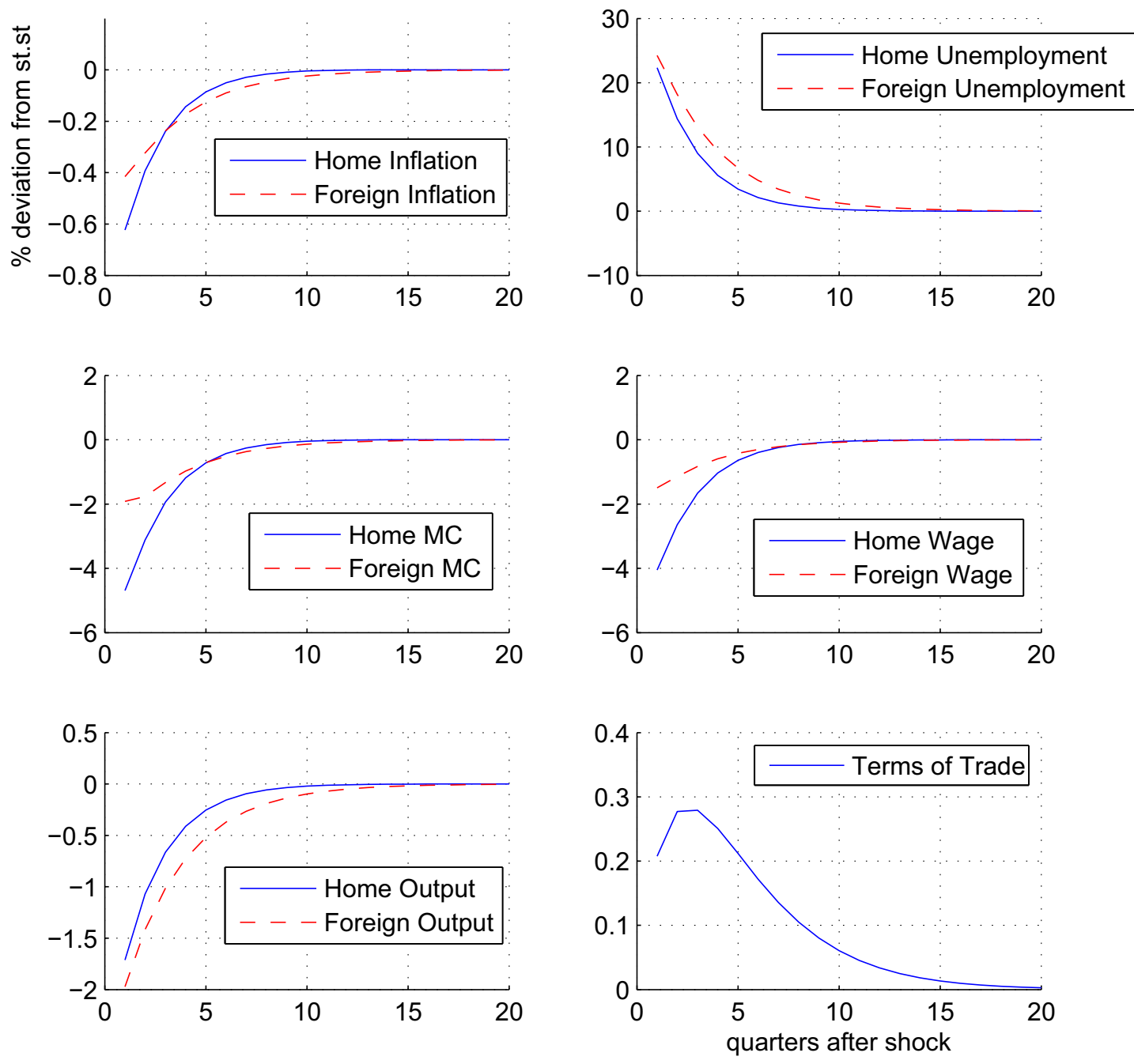

Figure 4: Impulse responses of selected domestic and foreign variables to common monetary policy shock 

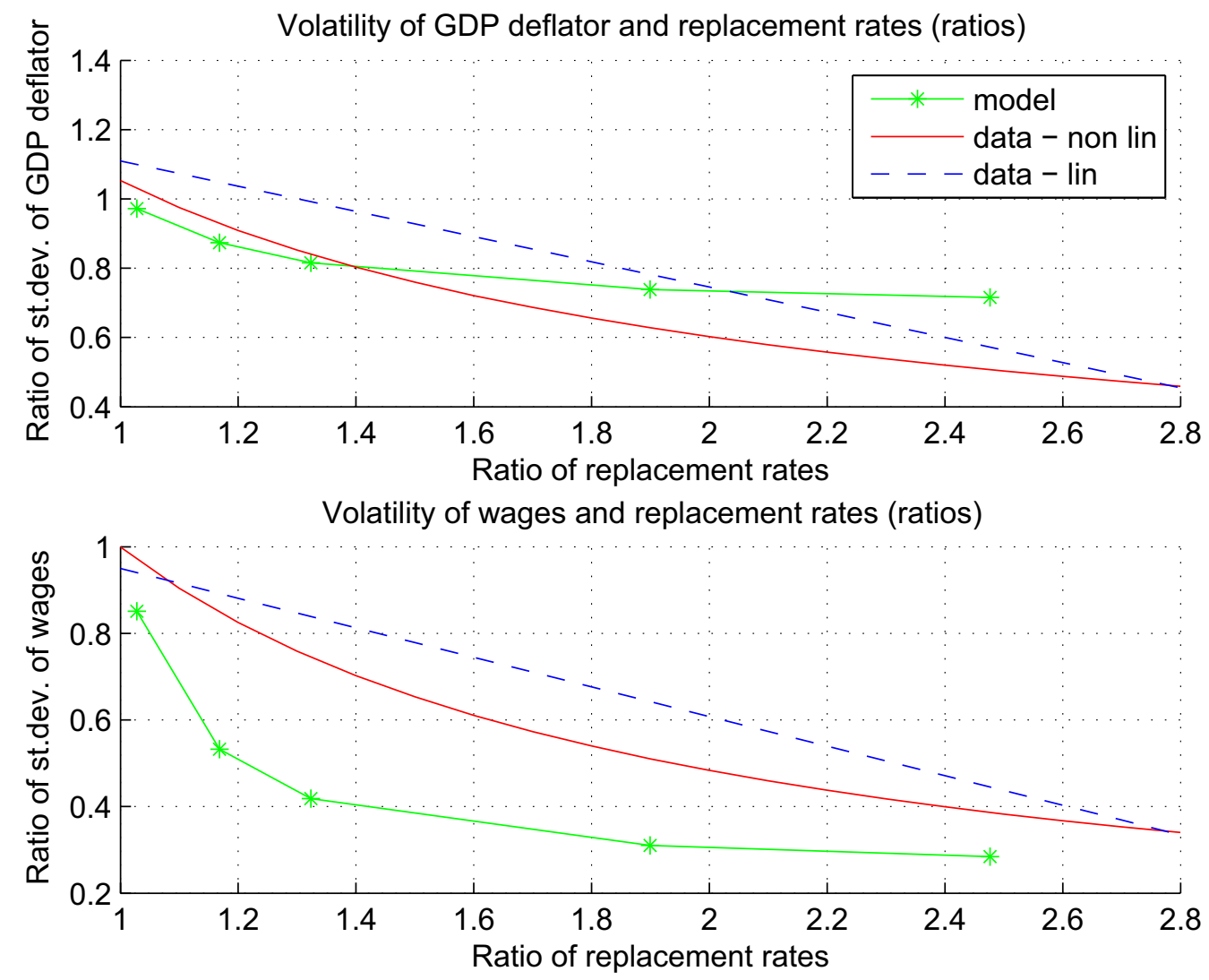

Figure 5: Relation between ratios of standard deviation of wages and inflation (relative to that of output) and ratios of replacement rates both in the data and in the model with endogenous separation rate. 

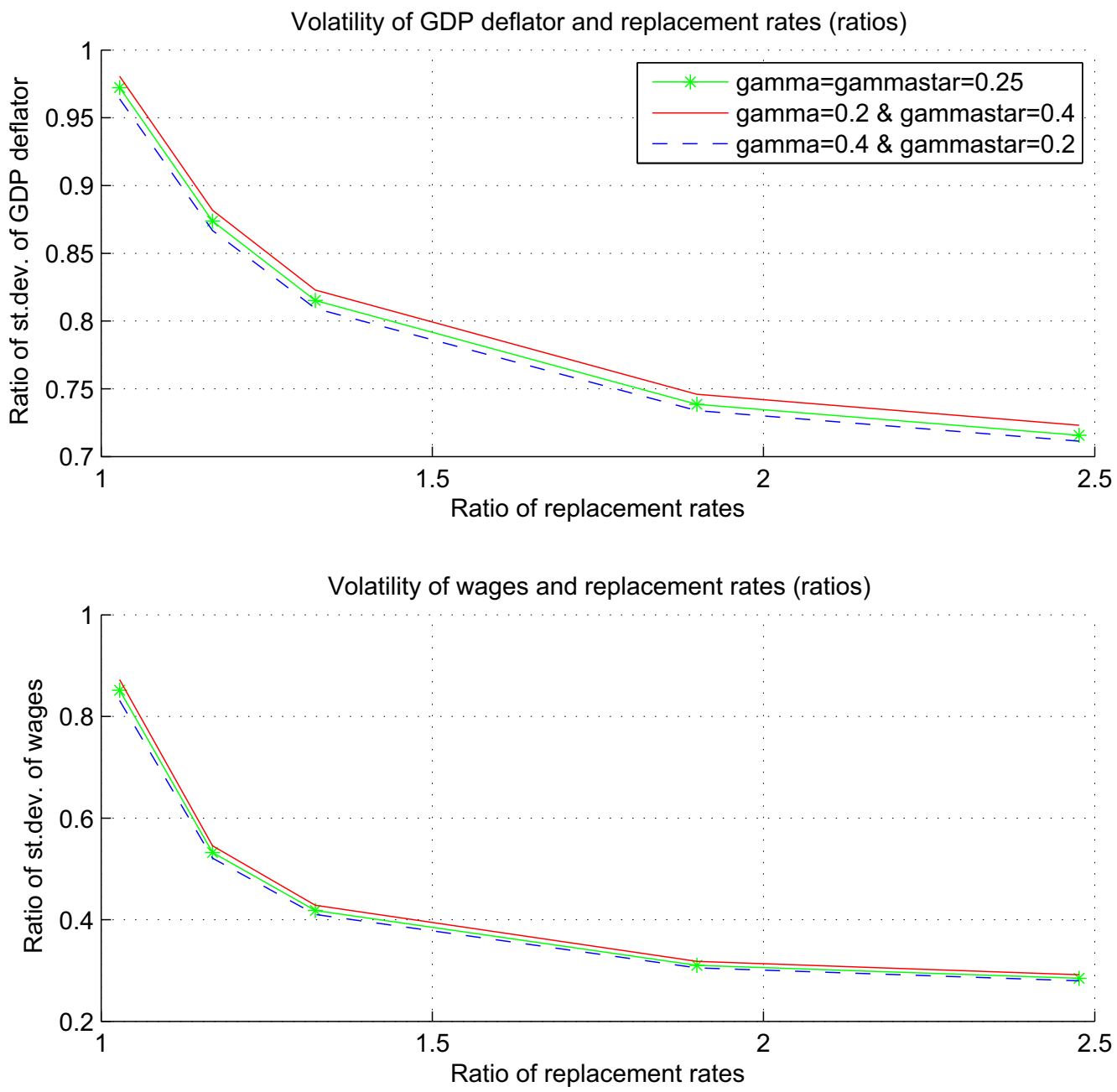

Figure 6: Relation between ratios of standard deviation of wages and inflation (relative to that of output) and ratios of replacement rates both in the data and in the model (assuming different degrees of trade openness between the two countries) 